\title{
The analysis of the Saltzman Collection of Peruvian dyes by high performance liquid chromatography and ambient ionisation mass spectrometry
}

\author{
Ruth Ann Armitage ${ }^{1 *} \mathbb{D}$, Daniel Fraser $^{2}$, Ilaria Degano ${ }^{3}$ and Maria Perla Colombini ${ }^{3}$
}

\begin{abstract}
Yarn samples from the Saltzman Collection of Peruvian dyes were characterized by several different analytical techniques: high performance liquid chromatography with both diode array detection (HPLC-DAD) and electrospray ionisation with tandem mass spectrometry (HPLC-ESI-Q-ToF), direct analysis in real time (DART) mass spectrometry and paper spray mass spectrometry. This report serves primarily as a database of chemical information about the colorants in these dye materials for those studying ancient South American textiles and their colorants. We also provide a comparison of the results obtained by currently widespread HPLC techniques with those of two different ambient ionisation direct mass spectrometry methods to highlight the advantages and disadvantages of these approaches.
\end{abstract}

Keywords: Natural dyes, HPLC, Ambient ionisation mass spectrometry, DART-MS, Peruvian dyes, Saltzman color collection

\section{Introduction}

Max Saltzman began his career in industrial color chemistry after the Second World War. From the 1960s, he consulted with museums and researchers to identify colorants in ancient textiles with the methods of the time, primarily solution ultraviolet-visible absorption spectroscopy. Following his retirement from the Allied Chemical Corporation in the early 1970s, he set up the Laboratory for Historical Colorants within the Institute of Geophysics and Planetary Physics at the University of California, Los Angeles. There he continued work on his lifelong interest in how people used color in the ancient world. According to Saltzman's colleague David McJunkin [1], Saltzman's interest in Andean textiles began while he was still working in industry, where he consulted with the American Museum of Natural History to identify shellfish purple in an ancient textile from

\footnotetext{
${ }^{*}$ Correspondence: rarmitage@emich.edu

${ }^{1}$ Department of Chemistry, Eastern Michigan University, Ypsilanti, MI 48197, USA

Full list of author information is available at the end of the article
}

Peru. One of the laboratory's first major projects in the 1970s resulted in the Saltzman Collection of Peruvian dyes, a notebook containing recipes and descriptions of materials collected and prepared by Saltzman. The notebook, currently held in the collections at UCLA, also contains skeins of wool (not specified, but presumably from domestic sheep), alpaca and cotton yarns, prepared by either Dr. Saltzman himself or more likely one of his associates. The notebook records the recipes used for the dye preparations and some indications of the mordanting processes, as well as information about where the botanical materials were collected in Peru and later archived. The information in the notebook about the materials was transcribed and is provided in Additional file 1 of this paper; no description of the alum mordanting process (i.e., premordanting vs. combining the mordant with the dye) was recorded in the notebook. The materials archived from Saltzman's studies, including the Collection studied here, have provided reference materials for researchers around the world.

Saltzman laid the foundation of analysis of dyes in textiles from ancient South America through the use of 
solution UV and visible spectrophotometry, comparing the resulting spectra of the extracts from fragments of ancient textile samples with those obtained on known materials $[2,3]$. He well understood the limitations of that approach, however, and presciently predicted that separation and mass spectrometry would eventually be the preferred approach to dyes analysis [2]. Microspectroscopy, with both ultraviolet-visible and infrared light, has also provided insight into the nature of dyes in Peruvian textiles $[4,5]$. While separation by thin-layer chromatography is somewhat useful in the analysis of ancient dyes from Peru [6], high performance liquid chromatography coupled with UV-vis detection is more common. Wouters and Rosario-Chirinos [7] described the analysis of a variety of different colors found in pre-Columbian Peruvian textiles with HPLC and diode array UV-vis detection. Combinations of methods have shed further light on the ornate textiles and other objects from mummy bundles from South America [8]. Mass spectrometry with ambient ionisation [9] has shown that plant dyes from Relbunium species can be identified rapidly in Paracas textiles, confirming results first reported by Saltzman [10]. Burr [11] demonstrated the use of surface enhanced Raman spectroscopy (SERS) to differentiate between the plant and insect red dyes used in ancient Peru using only single fibers.

For analysis of dyes in archaeological materials generally, HPLC is arguably the most commonly used method, with mass spectrometric detection becoming accessible to more laboratories in recent years. Tandem mass spectrometry is particularly useful for the identification of unknown dye colorants, as the fragmentation patterns are more easily differentiated than are UV-visible spectra obtained from diode array detectors. Indeed, HPLCMS/MS is the best and most comprehensive approach to identification of dyes in cultural heritage materials. The main drawback of all HPLC studies is the long time necessary to extract or otherwise prepare the sample followed by what is generally a lengthy separation. The speed of the analysis is offset by the comprehensive nature of the results. Moreover, sample treatment is a key issue; thus, in the last 10 years research has focused on strategies to maximize the information obtainable from a single microsample by purifying and pre-concentrating the analytes, while avoiding harsh treatments which might alter the molecular profile of the samples [12-16]. The most widespread method entailed hydrolysis in an acidic (generally $\mathrm{HCl}$ ) methanolic solution, in a heated bath, sometimes aided by ultrasound or microwaves. In the last 10 years, mild extraction methods were developed, entailing the use of organic acids acting as complexation agents such as hydrofluoric, formic, oxalic, trifluoroacetic, or acetic acid, alone or combined with
EDTA. These methods were developed to overcome the issues caused by the application of strong acidic conditions, such as cleavage of glycosidic bonds, dehydration or decarboxylation or of molecular markers, and esterification of phenolcarboxylic compounds [12].

Direct analysis in real time (DART) is an ambient (open air) ionisation technique that was developed to work with high-resolution time-of-flight mass spectrometry for rapid analysis of small molecules without the need for sample preparation [17]. Like all analytical methods, it has limitations. Molecular mass alone cannot be used to differentiate between isomers with the same empirical formula, a significant issue in the identification of many dye colorants. HPLC allows such differentiation based on retention time, and often the UV-visible spectrum is sufficient for identification. What direct mass spectrometry lacks in selectivity, it makes up for in sensitivity and speed. The primary advantage of DART-MS and other ambient ionization methods is that they are fast: analysis is complete in a matter of seconds. Additionally, by avoiding sample preparation, the analysis can encompass all ionisable compounds present, not just those soluble in the extraction solvent. Paper spray is a more recent development in ambient ionization techniques, first published by Liu et al. [18]. A form of electrospray ionization, paper spray makes molecules that are not readily ionized with DART accessible in a low-volume format. The Armitage group has pioneered the use of DART-MS for analysis of natural dyes for applications to ancient textiles [9, 19-22] and other cultural heritage materials [23-25]. While paper spray has been used by others for characterizing both natural and artificial colorants in food and beverage $[26,27]$, this is the first instance of which we are aware for its use in heritage science applications. We present here the results of using DART-MS and paper spray MS for identifying the colorants in a selection of the Peruvian dye samples from the Saltzman Collection, along with HPLC-DAD and HPLC-ESI-Q-ToF analyses for comparison and validation of the results. The materials from the Peruvian dyes collection prepared and documented by Max Saltzman include reference yarns dyed with three Relbunium species, cochineal, and three yellow plant dyes. Literature data available for the composition of the investigated dyes together with the known characteristic biomolecular markers are reported in Table 1.

\section{Materials and methods}

The work described here relates to a selection of the dyes in the Saltzman Collection that were sampled in May 2014 by two of the authors at UCLA (MPC and RAA). Yarn specimens were selected from materials dyed with eight different dyes, four red and three yellow or brown, on wool and alpaca both with and without alum 
Table 1 Characteristic compounds of the dye materials in the Saltzman Collection

\begin{tabular}{|c|c|c|c|c|c|c|c|}
\hline Dye source & Marker & Formula & Molecular mass & {$[\mathrm{M}-\mathrm{H}]^{-}$} & {$[\mathrm{MH}]^{+}$} & {$[\mathrm{M}+\mathrm{Na}]^{+}$} & References \\
\hline \multirow[t]{12}{*}{ Relbunium spp. } & Purpurin & $\mathrm{C}_{14} \mathrm{H}_{8} \mathrm{O}_{5}$ & 256.037 & 255.029 & 257.045 & 279.027 & \multirow{12}{*}{$\begin{array}{l}\text { Cardon [34]: 164, Dutra Moresi } \\
\text { [33] }\end{array}$} \\
\hline & Xanthopurpurin & $\mathrm{C}_{14} \mathrm{H}_{8} \mathrm{O}_{4}$ & 240.042 & 239.034 & 241.050 & 263.032 & \\
\hline & Rubiadin/alizarin methyl ether & $\mathrm{C}_{15} \mathrm{H}_{10} \mathrm{O}_{4}$ & 254.058 & 253.050 & 255.066 & 277.048 & \\
\hline & Lucidin & $\mathrm{C}_{15} \mathrm{H}_{10} \mathrm{O}_{5}$ & 270.053 & 269.045 & 271.061 & 293.043 & \\
\hline & Munjistin & $\mathrm{C}_{15} \mathrm{H}_{8} \mathrm{O}_{6}$ & 284.032 & 283.024 & 285.040 & 307.022 & \\
\hline & Pseudopurpurin & $\mathrm{C}_{15} \mathrm{H}_{8} \mathrm{O}_{7}$ & 300.027 & 299.019 & 301.035 & 323.017 & \\
\hline & $\begin{array}{l}\text { 1-Methoxy-2-methylanthraqui- } \\
\text { none }\end{array}$ & $\mathrm{C}_{16} \mathrm{H}_{12} \mathrm{O}_{3}$ & 252.079 & 251.071 & 253.087 & 275.069 & \\
\hline & $\begin{array}{l}\text { 2-Methoxyanthraquinone or } \\
\text { 1-hydroxy-2-methylanth- } \\
\text { raquinone }\end{array}$ & $\mathrm{C}_{15} \mathrm{H}_{10} \mathrm{O}_{3}$ & 238.063 & 237.055 & 239.071 & 261.053 & \\
\hline & Xanthopurpurin primeveroside & $\mathrm{C}_{25} \mathrm{H}_{26} \mathrm{O}_{13}$ & 534.137 & 533.129 & 535.145 & 557.127 & \\
\hline & Rubiadin primeveroside & $\mathrm{C}_{26} \mathrm{H}_{28} \mathrm{O}_{13}$ & 548.153 & 547.145 & 549.161 & 571.143 & \\
\hline & Lucidin primeveroside & $\mathrm{C}_{26} \mathrm{H}_{28} \mathrm{O}_{14}$ & 564.148 & 563.140 & 565.156 & 587.138 & \\
\hline & $\begin{array}{l}\text { Galiosin (pseudopurpurin } \\
\text { primeveroside) }\end{array}$ & $\mathrm{C}_{26} \mathrm{H}_{26} \mathrm{O}_{16}$ & 594.122 & 593.114 & 595.130 & 617.112 & \\
\hline \multirow[t]{6}{*}{ Dactylopius coccus } & Carminic acid & $\mathrm{C}_{22} \mathrm{H}_{20} \mathrm{O}_{13}$ & 492.090 & 491.082 & 493.098 & 515.080 & \multirow{6}{*}{$\begin{array}{l}\text { Cardon [34]:624, Wouters and } \\
\text { Rosario-Chirinos [7], Statho- } \\
\text { poulou et al. [37], Wouters and } \\
\text { Verhecken [44] }\end{array}$} \\
\hline & $\begin{array}{l}\text { Flavokermesic acid (laccaic } \\
\text { acid D) }\end{array}$ & $\mathrm{C}_{16} \mathrm{H}_{10} \mathrm{O}_{7}$ & 314.043 & 313.035 & 315.051 & 337.033 & \\
\hline & Kermesic acid & $\mathrm{C}_{16} \mathrm{H}_{10} \mathrm{O}_{8}$ & 330.038 & 329.030 & 331.046 & 353.028 & \\
\hline & $\begin{array}{l}\text { Flavokermesic acid glucopyra- } \\
\text { nosides (dcll and dcofk) }\end{array}$ & $\mathrm{C}_{22} \mathrm{H}_{20} \mathrm{O}_{12}$ & 476.095 & 475.087 & 477.103 & 499.085 & \\
\hline & 4-Aminocarminic acid (dcIII) & $\mathrm{C}_{22} \mathrm{H}_{21} \mathrm{NO}_{12}$ & 491.106 & 490.098 & 492.114 & 514.096 & \\
\hline & $\begin{array}{l}\text { 2-C-a/b-glucofuranoside of } \\
\text { kermesic acid (dcIV and dcVII) }\end{array}$ & $\mathrm{C}_{22} \mathrm{H}_{20} \mathrm{O}_{13}$ & 492.090 & 491.082 & 493.098 & 515.080 & \\
\hline \multirow[t]{14}{*}{ Baccharis spp. } & Apigenin & $\mathrm{C}_{15} \mathrm{H}_{10} \mathrm{O}_{5}$ & 270.053 & 269.045 & 271.061 & 293.043 & \multirow{14}{*}{$\begin{array}{l}\text { Cardon [34]:233, Wouters and } \\
\text { Rosario-Chirinos [7]; Akaike } \\
\text { et al. [45] }\end{array}$} \\
\hline & Apigenin methyl ether & $\mathrm{C}_{16} \mathrm{H}_{12} \mathrm{O}_{5}$ & 284.068 & 283.060 & 285.076 & 307.058 & \\
\hline & Luteolin/kaempferol & $\mathrm{C}_{15} \mathrm{H}_{10} \mathrm{O}_{6}$ & 286.048 & 285.040 & 287.056 & 309.038 & \\
\hline & $\begin{array}{l}\text { Luteolin methyl ether/trihy- } \\
\text { droxymethoxyflavone/(iso) } \\
\text { kaempferide }\end{array}$ & $\mathrm{C}_{16} \mathrm{H}_{12} \mathrm{O}_{6}$ & 300.063 & 299.055 & 301.071 & 323.053 & \\
\hline & $\begin{array}{l}\text { Kumatakenin/luteolin dimethyl } \\
\text { ether }\end{array}$ & $\mathrm{C}_{17} \mathrm{H}_{14} \mathrm{O}_{6}$ & 314.079 & 313.071 & 315.087 & 337.069 & \\
\hline & $\begin{array}{l}\text { Tetrahydroxymethoxyflavone/ } \\
\text { (iso)rhamnetin/3-meth- } \\
\text { ylquercetin }\end{array}$ & $\mathrm{C}_{16} \mathrm{H}_{12} \mathrm{O}_{7}$ & 316.058 & 315.050 & 317.066 & 339.048 & \\
\hline & Salvigenin & $\mathrm{C}_{18} \mathrm{H}_{16} \mathrm{O}_{6}$ & 328.095 & 327.087 & 329.103 & 351.085 & \\
\hline & Eupalitin/betuletol & $\mathrm{C}_{17} \mathrm{H}_{14} \mathrm{O}_{7}$ & 330.074 & 329.066 & 331.082 & 353.064 & \\
\hline & Eupatorin/cirsilineol & $\mathrm{C}_{18} \mathrm{H}_{16} \mathrm{O}_{7}$ & 344.090 & 343.082 & 345.098 & 367.080 & \\
\hline & Dimethylquercetagetin & $\mathrm{C}_{17} \mathrm{H}_{14} \mathrm{O}_{8}$ & 346.069 & 345.061 & 347.077 & 369.059 & \\
\hline & $\begin{array}{l}\text { Sideritiflavone/jaceidin/cen- } \\
\text { taureidin }\end{array}$ & $\mathrm{C}_{18} \mathrm{H}_{16} \mathrm{O}_{8}$ & 360.085 & 359.077 & 361.093 & 383.075 & \\
\hline & $\begin{array}{l}\text { Quercetin-3-O-rutinoside } \\
\text { (rutin) }\end{array}$ & $\mathrm{C}_{27} \mathrm{H}_{30} \mathrm{O}_{16}$ & 610.153 & 609.145 & 611.161 & 633.143 & \\
\hline & Di-O-caffeoylquinic acid & $\mathrm{C}_{25} \mathrm{H}_{24} \mathrm{O}_{12}$ & 516.127 & 515.119 & 517.135 & 539.117 & \\
\hline & O-caffeoyl-feruloylquinic acid & $\mathrm{C}_{26} \mathrm{H}_{26} \mathrm{O}_{12}$ & 530.142 & 529.135 & 531.150 & 553.132 & \\
\hline \multirow[t]{4}{*}{ Hypericum spp. } & Dihydroxyxanthone & $\mathrm{C}_{13} \mathrm{H}_{8} \mathrm{O}_{4}$ & 228.042 & 227.034 & 229.050 & 251.032 & \multirow[t]{4}{*}{ Crockett et al. [39] } \\
\hline & Quercetin & $\mathrm{C}_{15} \mathrm{H}_{10} \mathrm{O}_{7}$ & 302.043 & 301.035 & 303.051 & 325.033 & \\
\hline & Quercetin glucuronide & $\mathrm{C}_{21} \mathrm{H}_{18} \mathrm{O}_{13}$ & 487.075 & 486.067 & 488.083 & 510.065 & \\
\hline & Methylquercetin glucuronide & $\mathrm{C}_{22} \mathrm{H}_{20} \mathrm{O}_{13}$ & 492.090 & 491.082 & 493.098 & 515.080 & \\
\hline \multirow[t]{2}{*}{ Kageneckia spp. } & Gallic acid & $\mathrm{C}_{7} \mathrm{H}_{6} \mathrm{O}_{5}$ & 170.022 & 169.014 & 171.030 & 193.012 & \multirow{2}{*}{$\begin{array}{l}\text { No previous reports on } K \text {. } \\
\text { lanceolata were found. } K \text {. } \\
\text { oblongata is described by Cas- } \\
\text { sels et al. [28] }\end{array}$} \\
\hline & Ursolic acid & $\mathrm{C}_{30} \mathrm{H}_{48} \mathrm{O}_{3}$ & 456.360 & 455.352 & 457.368 & 479.350 & \\
\hline
\end{tabular}


mordant. These samples were selected because they represent the majority of the materials in the Saltzman collection; we did not sample the cotton yarns due to there being much less material available. Samples (approx. $1 \mathrm{~cm}$ long) of each of the Saltzman collection yarns were cut from the skein and placed into a small zip-top plastic bag for transport to our respective laboratories. The samples listed in Table 2 were transferred immediately into glass vials for further storage at Eastern Michigan University to minimize plastic contamination. The samples brought to Pisa were stored in glass vials in the dark until analysis.

\section{HPLC-DAD and HPLC-ESI-Q-ToF analysis}

The sample pre-treatment prior to both HPLC-DAD and HPLC-ESI-MS analyses consisted of a mild extraction by dimethylformamide (DMF) and $0.1 \% \mathrm{Na}_{2}$ EDTA, $1: 1$ $(\mathrm{v} / \mathrm{v})$, as described by Manhita et al. [14] and Tiedemann and Yang [29], assisted by ultrasound, at $60^{\circ} \mathrm{C}$ for $60 \mathrm{~min}$. The supernatant was filtered with a PTFE syringe filter $(0.45 \mu \mathrm{m})$, and directly injected into the chromatographic system. The injection volume was $10 \mu \mathrm{L}$.

In order to confirm the nature of some species by breaking $O$-glycosidic bonds, we also applied a harsher extraction. The extraction solution was a 30:1 (v/v) mixture of methanol $(\mathrm{MeOH})$ with hydrochloric acid $(\mathrm{HCl})$. In particular, $300 \mu \mathrm{L}$ of $\mathrm{MeOH} / \mathrm{HCl}$ (30:1) solution were added to the sample; the extraction was performed at $60{ }^{\circ} \mathrm{C}$ for $60 \mathrm{~min}$ in an ultrasonic bath. The supernatant was filtered with a PTFE syringe filter $(0.45 \mu \mathrm{m})$, dried under a gentle stream of nitrogen and dissolved in $200 \mu \mathrm{L}$ of DMSO before injection in the chromatographic systems.

The HPLC-DAD system consists of a PU-2089 quaternary pump equipped with a degasser, an AS-950 autosampler, and an MD-2010 spectrophotometric diode array detector (all modules are Jasco International Co., Japan). ChromNav software was used to carry out data acquisition and data analysis. The diode array detector (DAD) operated with spectra acquisition in the range of 200-650 $\mathrm{nm}$ every $0.8 \mathrm{~s}$ with $4 \mathrm{~nm}$ resolution.

For the HPLC-MS analyses, an HPLC 1200 Infinity was used, coupled with a quadrupole-time of flight mass spectrometer Infinity Q-ToF 6530 detector by a Jet Stream ESI interface (Agilent Technologies, USA). ESI conditions were: drying and sheath gas $\mathrm{N}_{2}$, purity $>98 \%$, temperature $350{ }^{\circ} \mathrm{C}$, flow $10 \mathrm{~L} / \mathrm{min}$ and temperature $375{ }^{\circ} \mathrm{C}$, flow $11 \mathrm{~L} / \mathrm{min}$, respectively; capillary voltage $4.5 \mathrm{kV}$; nebulizer gas pressure $35 \mathrm{psi}$. The high resolution MS and MS/MS acquisition range was set from 100 to $1000 \mathrm{~m} / \mathrm{z}$ in negative mode, with acquisition rate 1.04 spectra/s. For the MS/MS experiments, $30 \mathrm{~V}$ were applied in the collision cell to obtain CID fragmentation (collision gas $\mathrm{N}_{2}$, purity $99.999 \%$ ). The FWHM (full width half maximum) of quadrupole mass bandpass used during MS/MS precursor isolation was $4 \mathrm{~m} / \mathrm{z}$. The Agilent tuning mix HP0321 was used daily to calibrate the mass axis. MassHunter ${ }^{\circledR}$ Workstation Software (B.04.00) was used to carryout mass spectrometer control, data acquisition, and data analysis. The anthraquinones were researched on the basis of their empirical formulas as $[\mathrm{M}-\mathrm{H}]^{-}$ions by the "Find by Formula" algorithm provided by the software. Formula matching was set at $5 \mathrm{ppm}$ tolerance with a limit extraction range of $1.5 \mathrm{~min}$ and an area filter of 500 counts. Formulas having an isotopic pattern score lower than $25 \%$ were discarded.

The eluents for the HPLC-DAD analyses were water and acetonitrile (ACN), both HPLC grade (Sigma Aldrich, USA), while the eluents for HPLC-ESI-Q-ToF analyses were water and acetonitrile, both HPLC-MS grade (Sigma-Aldrich, USA). All eluents were combined with $0.1 \% \mathrm{v} / \mathrm{v}$ formic acid (FA; $98 \%$ purity, J.T. Baker, USA). The chromatographic separation was performed for HPLC-DAD on an analytical column TC-C18(2) $(4.6 \times 150 \mathrm{~mm}$, particle size $5 \mu \mathrm{m}$, Agilent $)$ with a guard column TC-C18(2) $(4.6 \times 12.5 \mathrm{~mm}$, particle

Table 2 Materials from the Saltzman Collection of Peruvian dyes

\begin{tabular}{llll}
\hline Saltzman dye \# & Plant/insect genus and species & Color & Common name in Saltzman notebook \\
\hline 16 & Relbunium hypocarpium & Red & Antanco, chamiri, chapi-chapi \\
21 & Relbunium ciliatum & Red & Antanco? \\
10 & Relbunium sp. (unidentified) & Red & Antanco, chamiri, chapi-chapi \\
18 & Dactylopius coccus & Red & Cochineal \\
9 & Baccharis floribunda & Yellow & Chilca \\
25 & Hypericum larcifolium & Yellow & Chinchanco \\
$12 a$ & Kageneckia lanceolata & Yellow & Lloque \\
\hline
\end{tabular}

All samples tested were on either wool (not specified, assumed to be sheep's wool) or alpaca, both with and without alum mordant as described by Saltzman. See Additional file 1 for details of Saltzman's dyeing procedures

a Only alum mordanted yellow yarns were sampled, though iron mordanted gray yarns are also part of the collection 
size $5 \mu \mathrm{m}$, Agilent), flow rate of $1 \mathrm{~mL} / \mathrm{min}, \mathrm{T}=25{ }^{\circ} \mathrm{C}$. The program was $15 \%$ B for $5 \mathrm{~min}$, followed by a linear gradient to $50 \% \mathrm{~B}$ in $25 \mathrm{~min}$, then to $70 \% \mathrm{~B}$ in $10 \mathrm{~min}$ and finally to $100 \% \mathrm{~B}$ in $5 \mathrm{~min}$ (total run time $45 \mathrm{~min}$ ); re-equilibration time was $13 \mathrm{~min}$. Injection volume was $20 \mu \mathrm{L}$. For the HPLC-MS analyses, an Agilent Zorbax Extend-C18 column $(2.1 \times 30 \mathrm{~mm}$, particle size $1.8 \mu \mathrm{m})$ with an Extend-C18 precolumn $(2.1 \times 12.5 \mathrm{~mm}$, particle size $1.8 \mu \mathrm{m}$ ) was used for the chromatographic separation, flow rate $0.2 \mathrm{~mL} / \mathrm{min}$. The elution program was: $15 \%$ B for $1 \mathrm{~min}$, followed by a linear gradient to $50 \% \mathrm{~B}$ in $5 \mathrm{~min}$, then to $70 \% \mathrm{~B}$ in $2 \mathrm{~min}$; to $90 \% \mathrm{~B}$ in $7 \mathrm{~min}$ and finally to $100 \% \mathrm{~B}$ in $5 \mathrm{~min}$ (total run time $20 \mathrm{~min}$ ); reequilibration time was $5 \mathrm{~min}$. $\mathrm{T}=30^{\circ} \mathrm{C}$. Injection volume was $1 \mu \mathrm{L}$.

Both HPLC-DAD and HPLC-MS methods were already applied to several samples and case studies [30] including preliminary studies on some of the Saltzman dyes [31].

\section{DART-MS analysis}

Approximately $1 \mathrm{~mm}$ of the end of each yarn sample from the Saltzman Collection materials was cut off using a clean razor blade on a piece of glassine weighing paper, and the resulting loose fibers were divided roughly in half for analysis. The small fibers were collected under the microscope using cleaned fine-tip tweezers. The fibers were then introduced into the gap between the DART ionisation source (IonSense, Saugus, MA, USA) and Orifice 1 of the AccuTOF mass spectrometer (JEOL USA, Peabody, MA, USA). The helium DART gas was heated to $500{ }^{\circ} \mathrm{C}$, which has been shown to provide the highest sensitivity for most dye compounds, particularly in negative ion mode [21]. The mass spectrometer settings were selected for maximum intensity in the range of interest (150-1000 Da), and were also carried out in orifice switching mode (rapid switching between $-30 \mathrm{~V}$ and $-90 \mathrm{~V}$ at Orifice 1) to examine the fragmentation patterns. At $-30 \mathrm{~V}$, fragmentation is not observed and the primary species present is the $[\mathrm{M}-\mathrm{H}]^{-}$ion. At increasingly negative voltages, collision induced dissociation occurs, leading to increasing amounts of fragmentation. With Orifice 1 at $-90 \mathrm{~V}$, collision induced dissociation occurs, leading to a fragmentation pattern similar to that obtained under electron impact (EI) conditions used in GC-MS analysis. Because compounds of the same molecular formula yield identical spectra for the parent ion at $-30 \mathrm{~V}$, the fragmentation patterns at $-90 \mathrm{~V}$ can be used to differentiate structural isomers in pure substances. Application of this approach to mixtures results in complex spectra from overlapping fragments. In-source fragmentation using DART ionisation and the AccuTOF mass spectrometer has been validated for rapid forensic identification of pharmaceuticals [32], and efforts to use this approach for identifying dye components have been reported by the Armitage research group previously [9]. One half of the sample was analyzed directly without any treatment, while the second half was subjected to an addition of approximately $1 \mu \mathrm{L}$ of formic acid (88\%) prior to introduction into the DART ion source gap. Previous studies have shown that acid treatment yields a stronger signal for most dye colorants during DART-MS analysis [21, 22].

\section{Paper spray MS analysis}

Glycosides do not readily ionise by DART-MS due to the hydrogen bonding that occurs between the many hydroxyl groups. This was noticed previously in studies of carminic acid in yarns dyed with cochineal [21].To examine the glycosidic compounds, samples were extracted in $0.1 \% \mathrm{Na}_{2}$ EDTA in water/DMF (1:1 ratio by volume) as described by Manhita et al. [14] and Tiedemann and Yang [29]. A few millimeters of yarn (as for DART-MS) was placed into a microcentrifuge tube with $50 \mu \mathrm{L}$ of the extraction solution and sonicated at $60{ }^{\circ} \mathrm{C}$ for $60 \mathrm{~min}$ to extract the dye components. This is the same mild extraction procedure used for the HPLC analysis. The extracts were used for paper spray mass spectrometric analysis.

Paper spray is an ambient ionisation method that relies on an electrospray-like mechanism [18]. Paper spray-MS was carried out using a home-built ion source consisting of an alligator clip and filter paper (Whatman No. 4) electrode that was powered by the AccuTOF electrospray port. For the PS-MS, $+3500 \mathrm{~V}$ was applied to the paper electrode, with the Orifice 1 and ring lens voltages set to $+80 \mathrm{~V}$ and $+10 \mathrm{~V}$ respectively. The tip of the paper electrode was positioned in front of Orifice 1 on the AccuTOF. A $3 \mu \mathrm{L}$ aliquot of the extract was placed on the paper electrode for analysis.

Calibration of each data collection file for both forms of ambient ionisation was carried out with PEG-600 in methanol, and files were processed using TSSPro 3.0 software (Shrader Analytical and Consulting Laboratories, Detroit, MI, USA). Data analysis for all results from the AccuTOF mass spectrometer was undertaken with Mass Mountaineer software (various versions, RBC Software, provided by R.B. Cody). While the large volume of information obtained from the direct analysis might seem at first glance to be overwhelming, the Mass Mountaineer software provides a way to search the spectra for molecular ions by specific adducts based on a list of possible compounds. Lists of compounds for each of the dye sources in the Saltzman Collection were compiled based on the literature (as shown in Table 1) and were used to search the resulting ambient ionisation mass spectra based on the molecular mass using the 
Mass Mountaineer software. Search lists consist of a list of compound names along with empirical formulas that Mass Moutaineer then uses to compute exact monoisotopic masses. The software allows the user to specify a minimum threshold signal intensity as well as a mass tolerance for identification based on the expected adducts. For the results reported here, the minimum threshold was $0.7 \%$ relative abundance, the mass tolerance was 12 millimass units $( \pm 0.012 \mathrm{Da})$. In negative ion DART, lists were searched only for $[\mathrm{M}-\mathrm{H}]^{-}$species, while for paper spray protonated species and sodium adducts were specified. Revisions to the DART and PS-MS sample lists were made based on the results of the HPLC-MS analyses as well.

\section{Results and discussion}

The results obtained by a qualitative and semi-quantitative point of view by separative techniques will be first presented. The results obtained with ambient ionisation techniques will be then discussed for each class of dyestuffs, highlighting advantages and disadvantages with respect to the established HPLC-based techniques.

\section{Relbunium dyes}

Other local names for the various Relbunium-derived dyes include chchapi or chapi-chapi, as well as the Quechua chamiri. Using HPLC-diode array detection, Dutra Moresi and Wouters [33] observed a general absence of alizarin in their study of several species of Relbunium. Xanthopurpurin was determined to be an important colorant compound in the Relbunium-derived red dyes of South America.

\section{a. HPLC-DAD and HPLC-ESI-Q-ToF}

The analysed Relbunium red samples all contained anthraquinone dyestuffs, as reported in Table 3. With regard to the Relbunium unknown species (samples 10) and $R$. hypocarpium (sample 16), the main constituents of the coloring material are pseudopurpurin, munjistin, and purpurin, while no alizarin was detected, consistent with literature data. Unknown compounds of anthraquinone structure were also detected, along with xanthopurpurin in minor amounts. The species identified by HPLC-ESIQ-ToF are reported in Table 2.

The analysis by both HPLC-DAD and HPLC-ESI-QToF of the extracts of the samples highlighted some interesting features related to the matrix. By a qualitative point of view, no differences were highlighted between the samples dyed with or without alum as a mordant, nor between alpaca threads and woolen ones. From a semiquantitative point of view, in the case of Relbunium (see Fig. 1), some differences are highlighted between alpaca and wool that appear less pronounced depending on the presence of the mordant.

\section{b. DART-MS}

DART-MS under standard conditions (Orifice 1 at $-30 \mathrm{~V})$ cannot distinguish between alizarin and xanthopurpurin, as these two compounds are structural isomers (1,2- and 1,3-dihydroxyanthraquinone, respectively) that each yield a single peak for the $[\mathrm{M}-\mathrm{H}]^{-}$ion. The comparison of collision-induced dissociation tandem mass spectra (conditions optimized in previous publications) can help to clarify which isomer is present, as the fragmentation pattern differs for the two compounds: xanthopurpurin undergoes a loss of $\mathrm{CO}_{2}$ (44 Da) much more readily than does alizarin, resulting in a significantly different intensity for the m/z 195 peak, as first reported by Szostek et al. [35]. At $-90 \mathrm{~V}$ on Orifice 1, xanthopurpurin shows a significant fragment at m/z 195 at about the same intensity as the $\mathrm{m} / \mathrm{z} 211$ fragment, while alizarin shows almost no m/z 195 fragment, and a significant fragment at m/z 210. For the Saltzman collection Relbunium dyes, it seems certain that xanthopurpurin is present, due to the strong presence of the m/z 195 fragment in the CID spectra, which also show a fragment at $\mathrm{m} / \mathrm{z} 210$ that may derive from some other alizarin-like compound in the Relbunium dyes rather than from alizarin itself.

In addition to the xanthopurpurin, the other anthraquinone dye colorants characteristic of Relbunium were observed in the DART-MS spectra. The compounds are listed in Table 3 in order of their relative abundance. Because there is no sample preparation, variations in the concentrations of the colorants in the sampled material are expected. Many more of the dye colorant compounds are observed by DART-MS than by HPLC, demonstrating the sensitivity of the method. The distribution of the compounds observed do not seem to be correlated to either the mordant, fiber, or species of Relbunium used to prepare the dye.

\section{c. Paper spray MS}

The paper spray results showed low intensity peaks for a similar range of anthraquinone aglycone compounds as observed in the DART-MS spectra (Table 3). Glycosides were also observed in some of the spectra, usually as their sodium adduct ions. Based on the low signal intensities observed, particularly when compared to the DART results, paper spray is not the best ionisation method for detecting the compounds characteristic of Relbunium dyes. This may be due to the low concentration of the compounds and the low sensitivity of the PS-MS method under these conditions. However, glycosides that cannot 


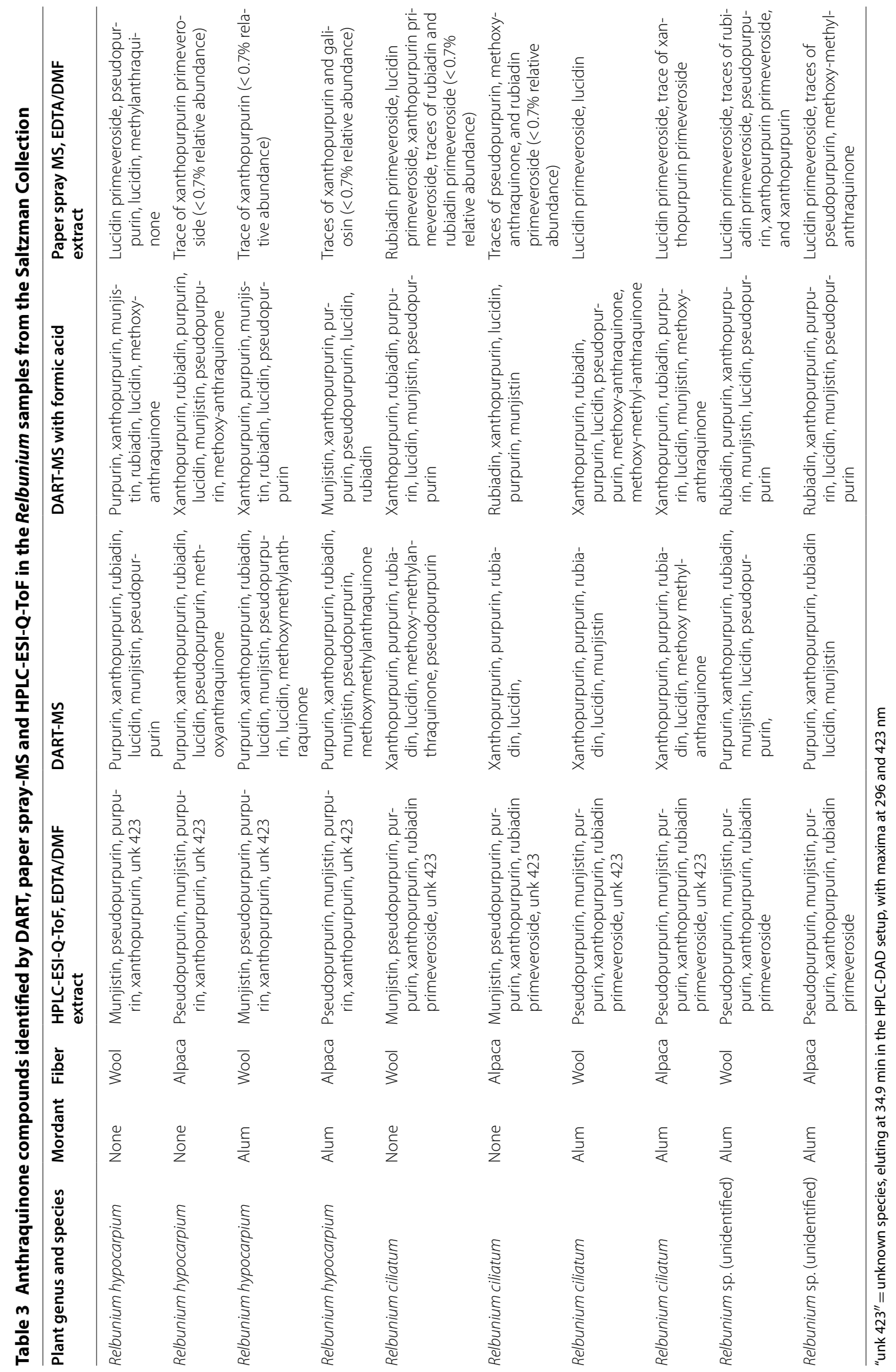




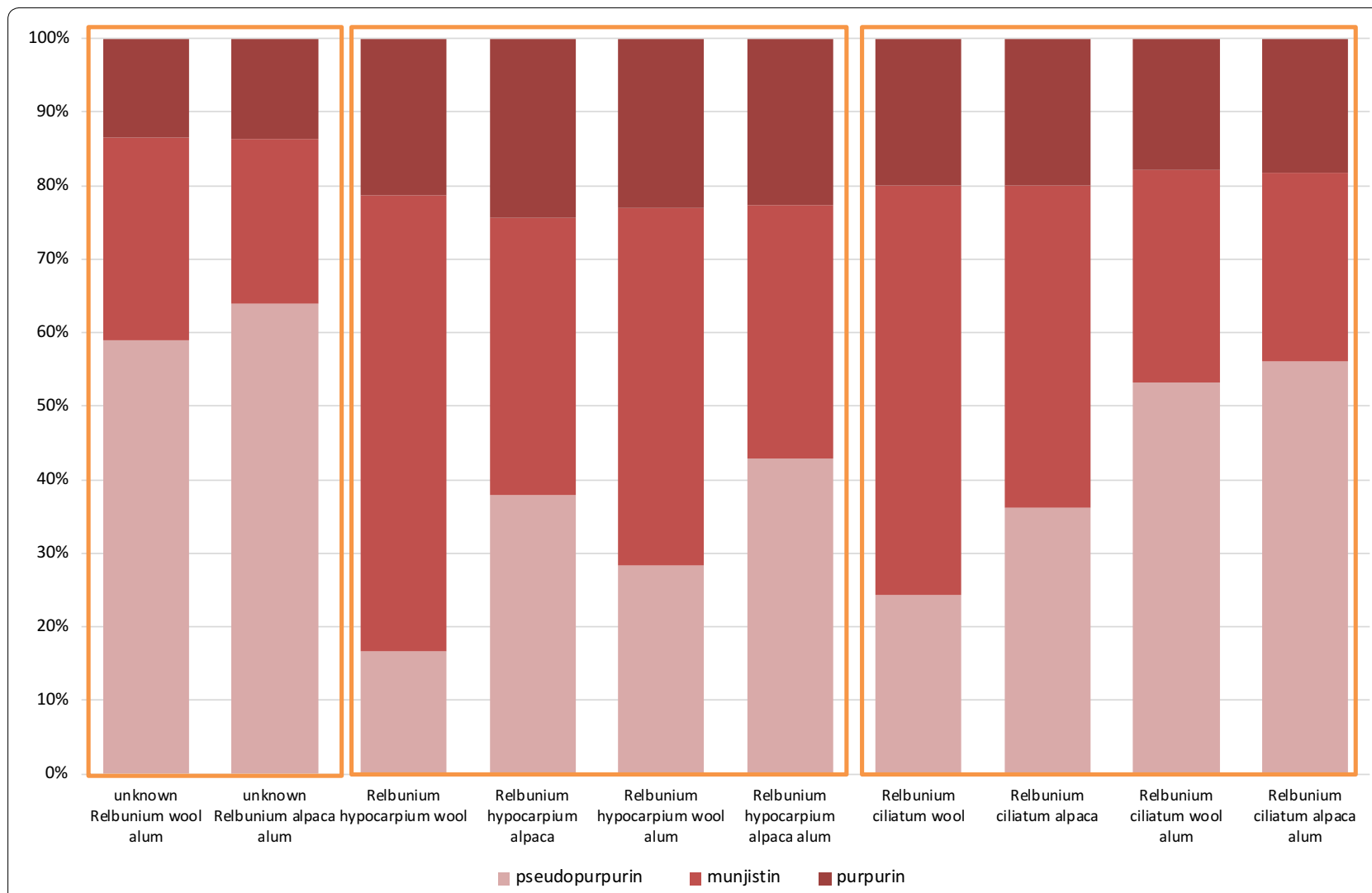

Fig. 1 Histogram of the relative composition of extracts of yarns dyed with different Relbunium species (samples 10, 16.1-16.4) based on the areas integrated at $254 \mathrm{~nm}$

be characterized with DART are present in the paper spray spectra. Many of the mild extraction procedures have been developed to preserve glycosides, which are thought to carry significant information about the botanical sources of dyes. Mouri and Laursen [36] describe such a procedure with HPLC to differentiate between various anthraquinone dye sources. An in-depth characterization of the glycosides in Relbunium dyes might provide a way of differentiating these species, but further work is needed to improve the PS-MS results.

\section{d. Discussion of Relbunium results}

The results for the Relbunium dyed samples showed the same major components by HPLC and DART-MS, though the relative intensities of the compounds were quite different. This is likely related to a combination of things including the extraction efficiency of the sample preparation needed for both HPLC and PS-MS and the ionization potentials under the different mass spectrometry conditions. The HPLC showed that purpurin, munjistin, and pseudopurpurin were the major components of the Relbunium plant dyes, while the DART indicated that purpurin and xanthopurpurin were the primary colorants, with xanthopurpurin dominating in the $R$. ciliatum and purpurin dominating in $R$. hypocarpium (example DART mass spectra are provided in Additional file 1). DART-MS also indicated the presence of several other minor anthraquinones that are reported in the literature as being characteristic of Relbunium dyes. The addition of the formic acid increases the overall signal in DART, but changes the relative intensities of the observed peaks, making differentiation of the species impossible under these conditions. Paper spray was not a good method for determining the Relbunium anthraquinones and their glycosides. All of the methods were capable of identifying the anthraquinone colorants characteristic of these plant red dyes.

\section{Cochineal dye \\ a. HPLC-DAD and HPLC-ESI-Q-ToF}

With regard to the two samples dyed with Dactylopius coccus, the analyses of the extracts showed the presence of the expected molecular markers for American cochineal. The semi-quantitative analysis of the different components did not highlight any striking difference between the alpaca and the wool dyed textiles. In both extracts, 
carminic acid was detected as the major peak in the chromatogram (c.a. $80 \%$ of the areas integrated at $275 \mathrm{~nm}$ ); dcII was around $7 \%$ while the minor components dcIII, dcIV, dcVII, kermesic and flavokermesic acids were detected below $5 \%$ each.

\section{b. DART-MS}

As previously observed, DART-MS does not reliably detect carminic acid and generally only traces of compounds characteristic of cochineal dye are observed by DART-MS directly [9]. More readily ionised minor components from cochineal, primarily kermesic acid, are often observed if the fibers are first treated with a few microliters of $88 \%$ formic acid, indicating that these compounds can provide some evidence of the presence of insect dyes. This is useful when the question is simply whether or not the red is plant- or insect-derived, but less so if one seeks to determine specifically what insect. For instance, kermes $(K$. vermilio) dyes are generally identified by the presence of kermesic and flavokermesic acid. The results of the DART (both with and without the formic acid treatment) and PS-MS analyses are provided in Table 4, and again are listed in order of relative intensity as observed in the spectra.

\section{c. Paper spray MS}

Paper spray MS on just three microliters of extract solution yielded results that differed only in terms of signal intensity from those obtained by ESI-MS, but without the need for pumps or additional solvent. The identified compounds in the paper spray mass spectra were present in most cases both as the $[\mathrm{M}+\mathrm{H}]^{+}$ion and as the $[\mathrm{M}+\mathrm{Na}]^{+}$ions. Because there is no separation, it is not possible to differentiate between isomeric species. Therefore, the peak at m/z 515.080 actually corresponds to the combined intensity for the sodium adducts of carminic acid and the glucofuranosides of kermesic acid [37] previously known in the literature as dcIV and dcVII. These kermesic acid glycosides occur at much lower abundance than carminic acid, about 5\% based on the HPLC study.

\section{d. Discussion of cochineal results}

Cochineal has long been well characterized by HPLC methods. The DART-MS results show that the absence of Relbunium anthraquinones and traces of cochineal aglycones in some cases can be indicative of this insect dye, but confirmation of carminic acid by ambient ionisation mass spectrometry required extraction and PS-MS analysis. The direct MS methods were capable of quickly differentiating between plant and insect reds, though full characterization is best done with a separative approach to determine the presence of the isomeric species.

\section{Baccharis floribunda}

According to Antúnez de Mayolo [38] and Cardon [23, p. 231], many different species of Baccharis have been used to make "chilca" dye. Using HPLC-DAD, Wouters and Rosario-Chirinos [7] found primarily luteolin, apigenin, and luteolin-like compounds, as well as ellagic acid, in reference samples dyed with Baccharis genistelloides. Cardon also suggests a large number of other compounds, the majority of which are included in Table 1, as components of dyes from the various Baccharis species.

\section{a. HPLC-ESI-Q-ToF}

All the analyzed yellow samples contained flavonoid dyestuffs as mainly reported in the literature $[7,39]$ and summarised in Table 1. A methanolysis-based sample treatment was applied in some cases in order to reduce the complexity of the samples to obtain the aglycones of all possible $\mathrm{O}$-glucosides. The chromatogram of the yarn

Table 4 Results for Dactylopius coccus (sample \#18) from Saltzman Collection

\begin{tabular}{|c|c|c|c|c|c|}
\hline Mordant & Fiber & $\begin{array}{l}\text { HPLC-ESI-Q-ToF, EDTA/DMF } \\
\text { extract }\end{array}$ & DART (no treatment) & DART (with formic acid) & $\begin{array}{l}\text { Paper spray MS, EDTA/DMF } \\
\text { extract }\end{array}$ \\
\hline None & Wool & $\begin{array}{l}\text { Carminic acid, dcll, flavokermesic } \\
\text { acid, kermesic acid, dcIll, dcIV, } \\
\text { dcVII }\end{array}$ & nd & nd & $\begin{array}{l}\text { Carminic acid/dcIV/dcVII, kermesic } \\
\text { acid, dcofk/dcll }\end{array}$ \\
\hline None & Alpaca & $\begin{array}{l}\text { Carminic acid, dcll, flavokermesic } \\
\text { acid, kermesic acid, dcIll, dcIV, } \\
\text { dcVII }\end{array}$ & nd & kermesic acid & $\begin{array}{l}\text { Carminic acid/dcIV/dcVII, kermesic } \\
\text { acid, dcofk/dcll }\end{array}$ \\
\hline Alum & Wool & $\begin{array}{l}\text { Carminic acid, dcll, flavokermesic } \\
\text { acid, kermesic acid, dcIll, dcIV, } \\
\text { dcVII }\end{array}$ & Kermesic acid & Flavokermesic acid, kermesic acid & $\begin{array}{l}\text { Carminic acid/dcIV/dcVII, kermesic } \\
\text { acid, dcofk/dcll, dcIll }\end{array}$ \\
\hline Alum & Alpaca & $\begin{array}{l}\text { Carminic acid, dcll, flavokermesic } \\
\text { acid, kermesic acid, dclll, dcIV, } \\
\text { dcVII }\end{array}$ & nd & Kermesic acid, flavokermesic acid & $\begin{array}{l}\text { Carminic acid/dcIV/dcVII, kermesic } \\
\text { acid, dcofk/dcll }\end{array}$ \\
\hline
\end{tabular}

nd not detected 
extracts contains quercetin as the main peak, quercetin methylether (the methoxy group is located on ring A, according to the interpretation of the tandem mass spectrum, but the peak does not correspond to rhamnetin, see Fig. 5) and luteolin methylether (based on the tandem mass spectrum, two hydroxyl groups are located on ring $\mathrm{A}$, while the methoxy group can be located on ring $\mathrm{B}$ or $\mathrm{C})$. Luteolin is present as a minor component, along with its dimethylether (the tandem mass spectrum was not acquired so no information on the position of substituents is available). Moreover, in the first half of the chromatogram, the most polar compounds elute, such as rutin. Three di-O-caffeoylquinic acid isomers (one possible structure is reported as an example in Fig. 2) and three $\mathrm{O}$-caffeoyl-feruloylquinic acid isomers are also detected. The TIC and extracted ion chromatograms corresponding to the identified species (or at least, molecular formulas) are reported in Fig. 3.

In the case of Baccharis floribunda dyed samples, the relative composition of the extracts, calculated as \% of the total sum of the areas integrated at $275 \mathrm{~nm}$, changes quite significantly between unmordanted and mordanted yarns, as reported in the histogram in Fig. 4. The relative abundance of rutin and of the caffeoylquinic acids is lower in the mordanted yarns' extracts than in the unmordanted ones. This may be due to the acidity induced by alum in solution, which may have caused a partial hydrolysis of the $O$-glycosidic bond.

\section{b. DART-MS}

Table 5 shows the DART-MS results for the four samples of chilca dye in the Saltzman collection. To simplify the results, only the compounds observed at $1 \%$ of the base peak or higher are listed in the table. At this time it is not possible to be specific which tetrahydroxymethoxyflavone is observed in the DART mass spectrum based on this information alone, though it is possible that collision induced dissociation (CID) might shed some light on the issue if standards of the various pure compounds can be obtained or synthesized in the future. The unambiguous identification of this compound as quercetin methyl ether was only possible thanks to the interpretation of the data obtained by high resolution tandem mass spectrometry. Interestingly, no luteolin $\left(\mathrm{m} / \mathrm{z}\right.$ 285.040, $\left.[\mathrm{M}-\mathrm{H}]^{-}\right)$was observed in the DART mass spectra. The closest mass peak was observed at $\mathrm{m} / \mathrm{z} 285.070$, a difference of $30 \mathrm{mil}-$ limass units, outside of the expected mass range. A close inspection of the raw signal shows several overlapping peaks in that region that were reduced to a single centroided peak in the TSSPro 3.0 data analysis software.

\section{c. Paper spray MS}

There was significant overlap in the compounds observed by paper spray MS with those found by DART-MS. The glycoside rutin and dicaffeoylquinic acid, a phenolic compound, were observed only in the PS-MS spectra. Based on their structures, this is as expected, as they would be unlikely to ionise directly by DART. The strong signal at $\mathrm{m} / \mathrm{z} 315.080$ in the paper spray spectra, often the base peak, corresponds to the sodium adduct of EDTA, a major component of the extraction solution. This is a major interference with the flavonol kumatakenin and should be taken into consideration when interpreting PS-MS spectra of EDTA-DMF extracts, particularly of natural yellow dyes.

\section{d. Discussion of Baccharis results}

The primary colorant in the Baccharis-dyed yarns identified by the HPLC analysis was luteolin, though luteolin was not identified at all in the DART-MS analyses. This may be attributed to the resolution of the AccuTOF mass spectrometer; the signal at $\mathrm{m} / \mathrm{z}$ 285.070 may be the combination of luteolin and an unknown interfering mass too close to be resolved by<smiles>COc1cc(/C=C/C(=O)O[C@@H]2C[C@](O)(C(=O)O)C[C@H](O)[C@H]2OC(=O)/C=C/c2ccc(O)c(O)c2)ccc1O</smiles>

Fig. 2 Structure of one di-O-caffeoylquinic acid (on the left) and one O-caffeoyl-feruloylquinic acid (on the right) 


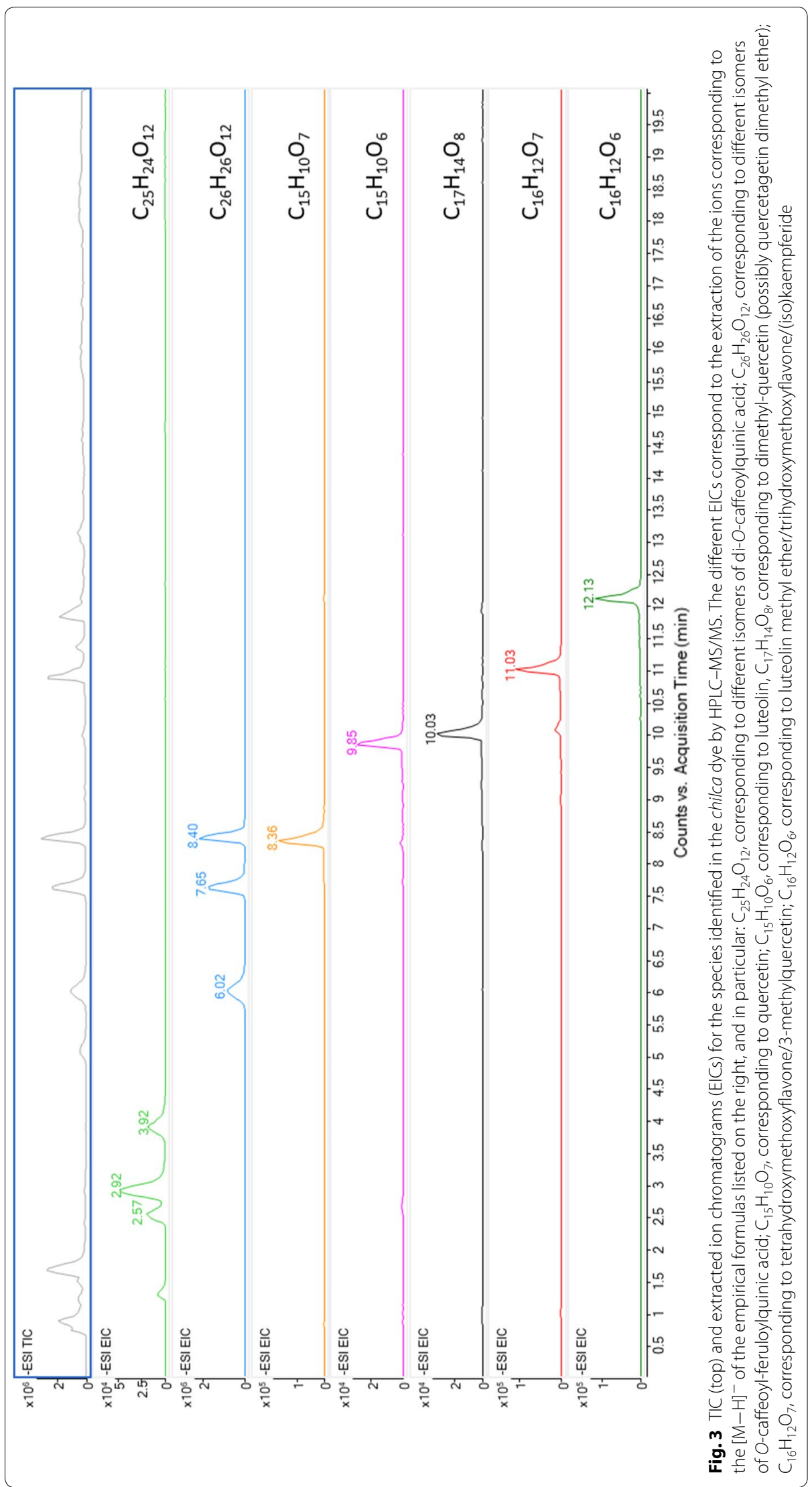




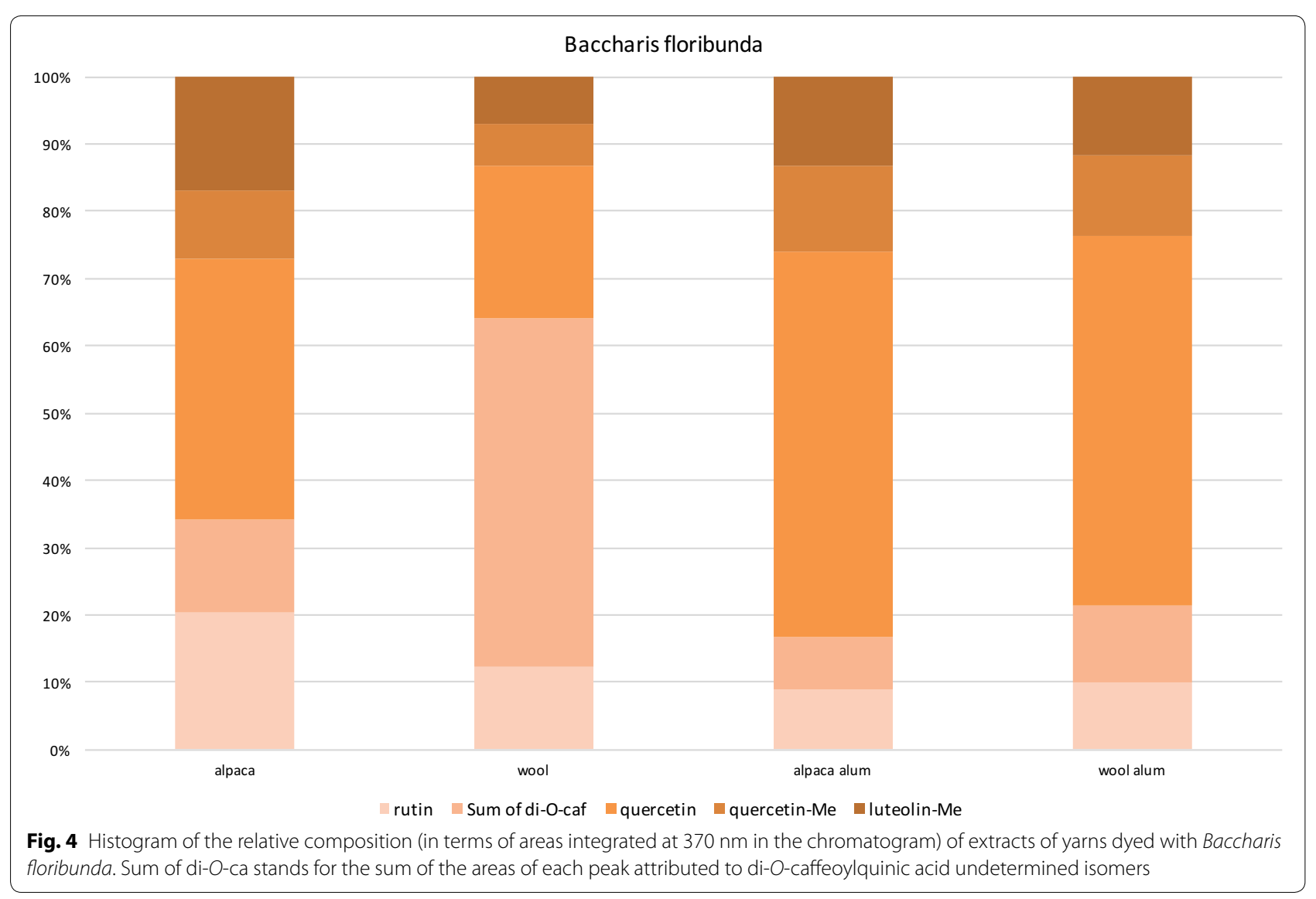

the AccuTOF (see the DART mass spectrum for the Baccharis sample provided in Additional file 1). The observed signal is 0.030 mass units different from luteolin (which should be observed at $\mathrm{m} / \mathrm{z} 285.040$ as the $\mathrm{M}-\mathrm{H}$ anion), well outside of the allowed tolerance for identifying this peak. Otherwise, the DART-MS and the HPLC gave mostly similar results. Yellow dyes are difficult to identify, as there are so many available all with overlapping compositions. The structures of the many overlapping flavonoid isomers expected in Baccharis are shown in Additional file 1. For definitive identification of an unknown yellow dye, multiple techniques, both with and without separation, are needed.

\section{Hypericum larcifolium}

Unlike most of the other Andean dyes, Cardon [34] does not provide a detailed discussion of the use of Hypericum species, other than listing "chinchanko" on a list of dyes found in a Jesuit administrative document from Quito dating to the early $18^{\text {th }}$ century. According to both Hofenk de Graaf [40] and Crockett et al. [39], the flavonoid compounds present in Hypericum are primarily quercetin and its many glycosides, along with a number of xanthones. The distribution of these compounds in the chinchanco dye samples from the Saltzman Collection is shown in Table 6.

\section{a. HPLC-ESI-Q-ToF}

The HPLC-ESI-Q-ToF chromatograms obtained for the analysis of Hypericum larcifolium, feature methylquercetin glucuronide $(60-70 \%$ with respect to the areas integrated at $254 \mathrm{~nm}$ ), while quercetin glucuronide and quercetin are present as minor components (25-30\% and 5-10\% respectively). Hypericin and hyperforin are compounds characteristic of the genus Hypericum, yet they were not detected even at low levels in the dyed fibers. The semi-quantitative analysis of the 


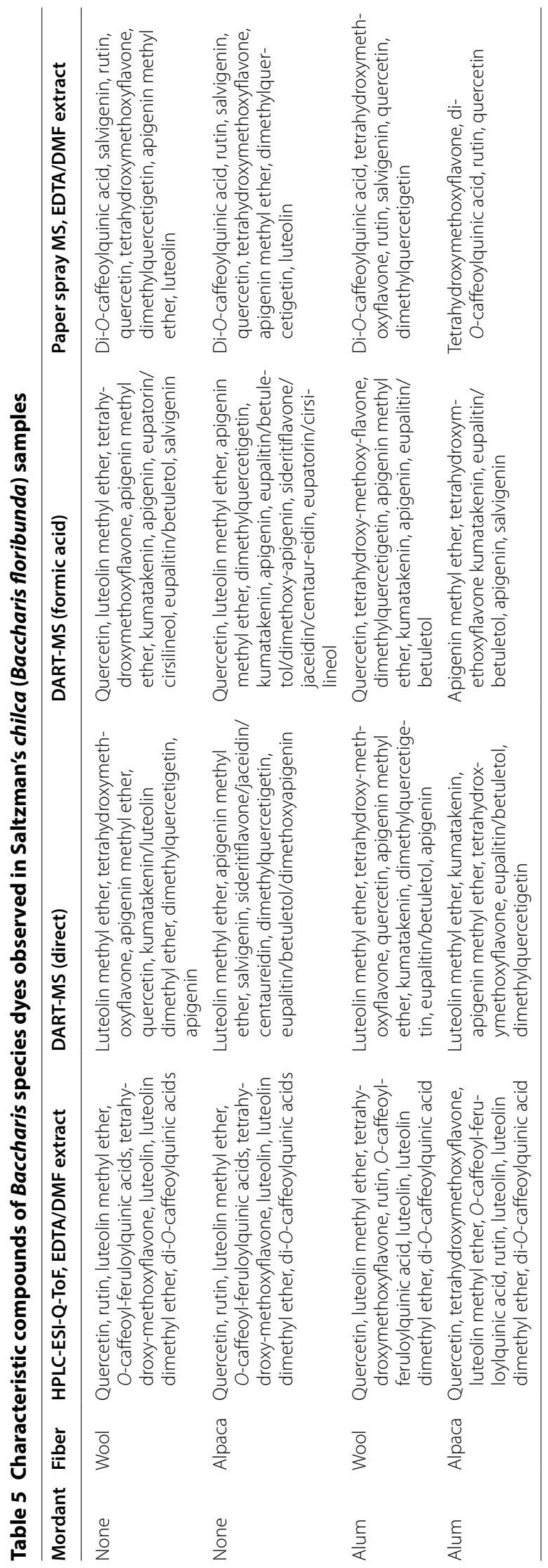




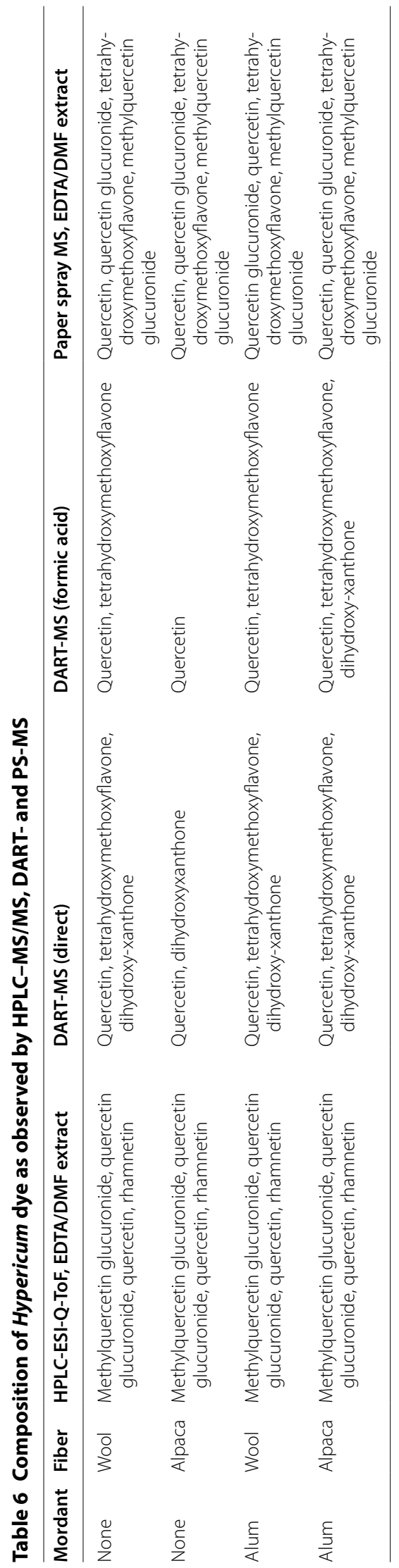




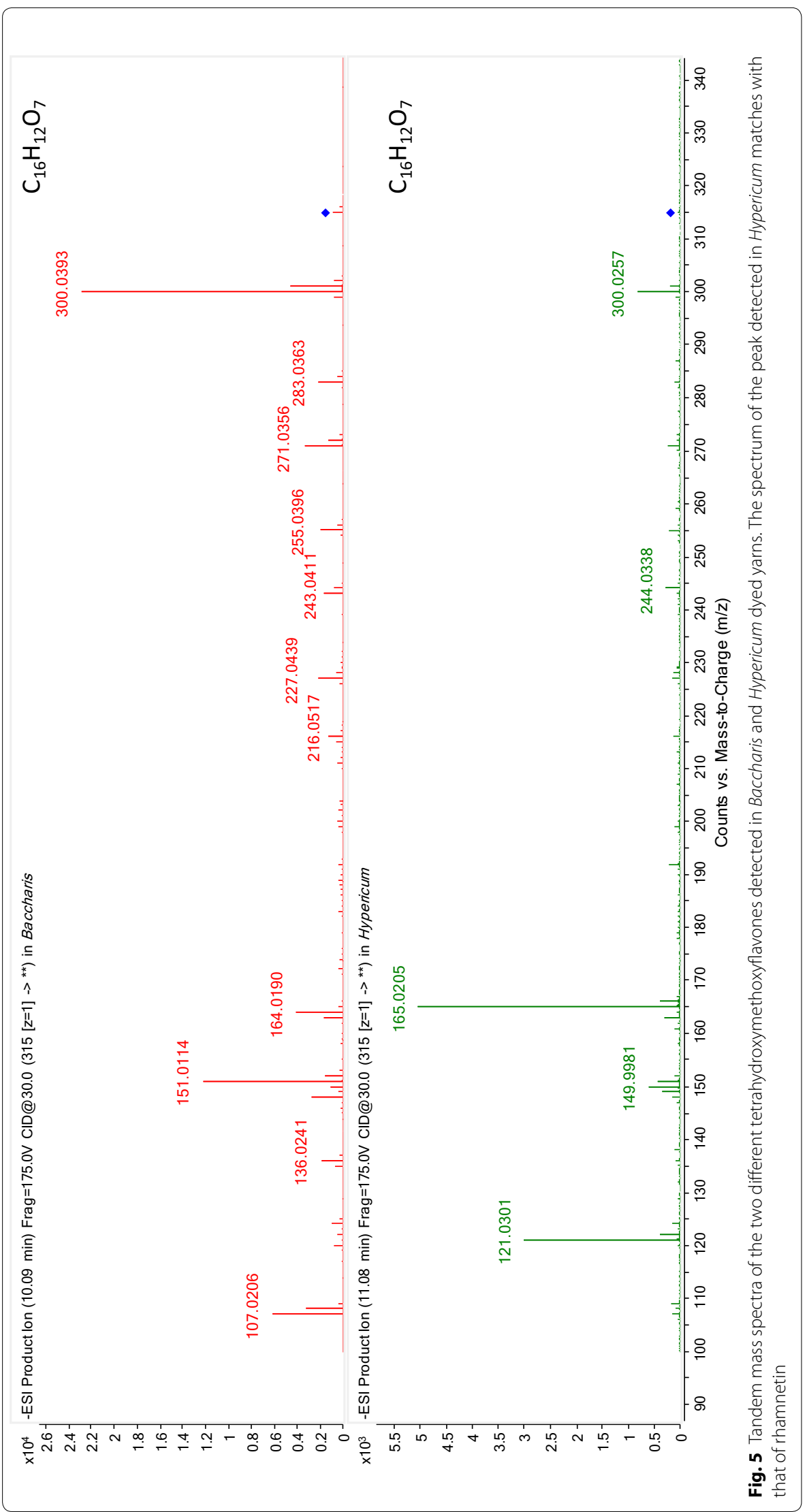


different components did not highlight any striking difference between the alpaca and the wool dyed textiles, nor between the mordanted unmordanted fibres. A tetrahydroxymethoxyflavone, in particular rhamnetin, was determined in the Hypericum dyed textile that has both a different retention time and an MS-MS spectrum from those of the quercetin methyl ether peak detected in $\mathrm{Bac}$ charis dyed sample (see spectra in Fig. 5).

\section{b. DART-MS results}

Hypericin and hyperforin are not detected even at low levels in the dyed fibers by DART-MS, as highlighted also for HPLC-ESI-Q-ToF results. The peak at $\mathrm{m} / \mathrm{z}$ 301.035, presumably quercetin, dominates the DART mass spectrum. Because the signal for this compound is so strong compared to other ions observed in the spectrum, a fragmentation pattern at $-90 \mathrm{~V}$ can be used to determine if this is actually quercetin. Figure 6 shows the observed CID-DART spectra for the unmordanted wool sample dyed with $H$. larcifolium and that of quercetin standard. This strongly indicates that the ion at $\mathrm{m} / \mathrm{z} 301.035$ corresponds to the $[\mathrm{M}-\mathrm{H}]^{-}$of quercetin, as was confirmed with HPLC. The DART mass spectra at both -30 and $-90 \mathrm{~V}$ for a quercetin standard are provided in Additional file 1.

\section{c. Paper spray MS}

The aglycones of quercetin and a tetrahydroxymethoxyflavone identified by DART-MS were also observed by paper spray. In addition, the glucuronides of both of

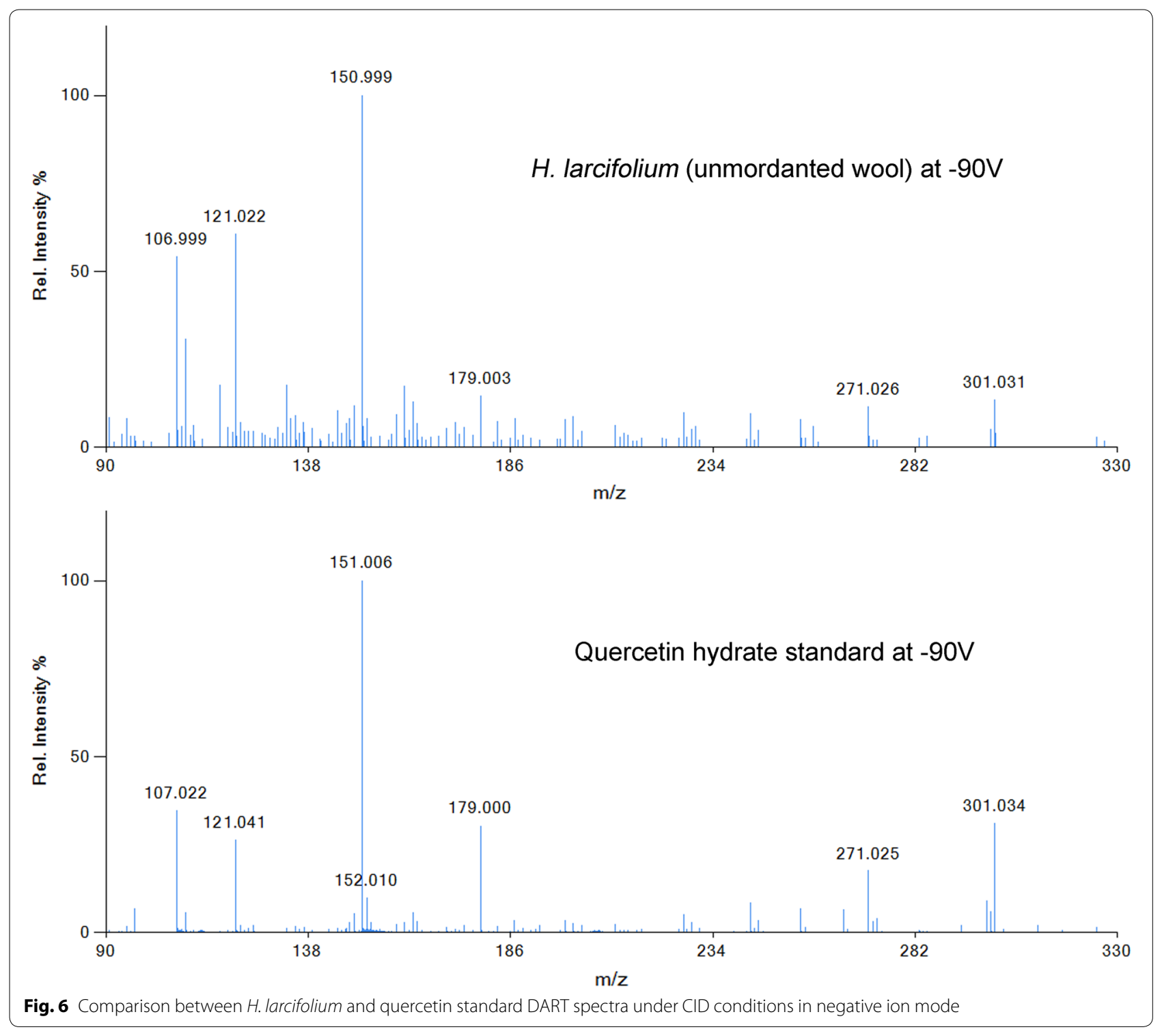


those compounds were present in all of the Hypericum dyed samples.

\section{d. Discussion of Hypericum results}

The results from the HPLC and PS-MS from the Hypericum-dyed yarns were effectively the same for this relatively simple dye. DART-MS was unable to identify the glycosides, as expected. However, because the spectrum was dominated by the signal at $\mathrm{m} / \mathrm{z} 301.080$, fragmentation at $-90 \mathrm{~V}$ on Orifice 1 of the AccuTOF confirmed that this major component was indeed quercetin rather than one of the other isomeric flavonoids. The DART mass spectra for the Hypericum samples were clearly different from those obtained for the Baccharis, making this method a fast way to differentiate between these two yellow dyes without additional sample preparation.

\section{Kageneckia lanceolata}

Cardon [34] mentions neither the plant Kageneckia lanceolata nor lloque or loque dye amongst the many South American dyes discussed. Mayolo [38] lists the plant leaves amongst a list of Peruvian natural dyes, and cites a number of early twentieth century references to it being used to produce a black dye, as does Towle [41]. The Saltzman samples on unmordanted fibers and with alum mordant were yellow; with iron mordant (not analyzed in this study), Saltzman's samples were only grey at the darkest shades obtained. There apparently has been no previous chemical characterization of lloque, which appears to be a tannin-based dye, though whether they are condensed or hydrolysable remains unclear. Towle [41] also reported that infusions of the leaves and bark of $K$. lanceolata were used as a treatment for fever. Though no reports on the composition of lloque dyes were found, several studies have been published on the active ingredients of Kageneckia in traditional South American medicinal practice. Phytochemical analysis of the leaves of Kageneckia species have focused primarily on the triterpenoids and their glycosides [28, 42, 43], with ursolic acid, $\mathrm{C}_{30} \mathrm{H}_{48} \mathrm{O}_{3}$, in the highest abundance.

\section{a. HPLC-ESI-Q-ToF analysis}

The chromatograms of the extracts of the yarns dyed with $K$. lanceolata are the simplest amongst the yellow dyes, and only contain quercetin as a minor component, and rutin as the major one. Also in this case, the semiquantitative analysis of the different components did not highlight any striking difference between the alpaca and the wool dyed yarns, nor between the mordanted and unmordanted fibres. No traces of triterpenoids were detected in the liquid chromatography based analyses, since the adopted sample treatment and elution gradient do not allow their determination. The observed compounds are listed in Table 7.

Among the minor components (Fig. 7), one peak corresponding to the empirical formula $\mathrm{C}_{16} \mathrm{H}_{12} \mathrm{O}_{5}$ was detected $\left([\mathrm{M}-\mathrm{H}]^{-}=283.0612\right)$; four peaks corresponding to the empirical formula $\mathrm{C}_{16} \mathrm{H}_{12} \mathrm{O}_{6}\left([\mathrm{M}-\mathrm{H}]^{-}=299.0561\right)$; two corresponding to the empirical formula $\mathrm{C}_{17} \mathrm{H}_{14} \mathrm{O}_{6}$ $\left([\mathrm{M}-\mathrm{H}]^{-}=313.0718\right)$. The corresponding tandem mass spectra are reported in Additional file 1: Figures S1-S3.

The four species with empirical formula $\mathrm{C}_{16} \mathrm{H}_{12} \mathrm{O}_{6}$ (Fig. 7c, Additional file 1: Figure S2) are all characterized by the loss of methyl and of $\mathrm{CO}_{2}$. All of them feature the ions at $\mathrm{m} / \mathrm{z} 151.00$ and 107.01, corresponding to ring $\mathrm{A}$ with two hydroxy substituents. This confirms the hypothesis that one of the species is kaempferide and one isokaempferide; the identification of the two other species is not as straightforward, due to the lack of proper analytical standards.

The two species corresponding to the empirical formula $\mathrm{C}_{17} \mathrm{H}_{14} \mathrm{O}_{6}$ (Fig. $7 \mathrm{~d}$ ) are characterized by tandem mass spectra with a fragment ion at $\mathrm{m} / \mathrm{z} 283$, corresponding to the A ring with 2 hydroxy and one methoxy substituent. They each present a much different fragmentation (see Additional file 1: Figure S3); the more polar one presents several fragment ions while the one eluting later only features the loss of one and two methyl groups, the following loss of $\mathrm{CO}$ and the ion due to ring $\mathrm{A}$.

\section{b. DART-MS}

While condensed tannins cannot be detected by DARTMS, tannin dyes characterized by this method often show a significant amount of gallic acid present; all of the Kageneckia dyes in the Saltzman Collection (except the unmordanted wool fibers treated with formic acid) clearly showed a small amount (around 1\% relative abundance) of gallic acid.

Prior to treatment with formic acid, ursolic acid (or another compound at $\mathrm{m} / \mathrm{z} 455.353$, possibly dammarane 2 observed by Lopéz-Peréz et al. [42], which has the same formula) is present in as much as $22 \%$ relative abundance (peak intensity ratio to base peak) in the Kageneckia samples. Benthamic acid, $\mathrm{C}_{33} \mathrm{H}_{52} \mathrm{O}_{5}$, was identified only in the unmordanted wool sample (as the $[\mathrm{M}-\mathrm{H}]^{-}$at $\mathrm{m} / \mathrm{z}$ 527.365). Based on the HPLC-MS/MS results, the major components of the DART mass spectra were identified as methyl apigenin (at $\mathrm{m} / \mathrm{z} 283.063$ ), kaempferide and/or isokaempferide (at $\mathrm{m} / \mathrm{z} 299.056$ ), and the as-yet uncharacterized compound at $\mathrm{m} / \mathrm{z} 313.071$. In the case of a dye for which no previous studies have been published, the analysis would best be carried out using HPLC-MS/MS, to determine the masses and fragmentation patterns for each of the separated compounds. However, based on the 


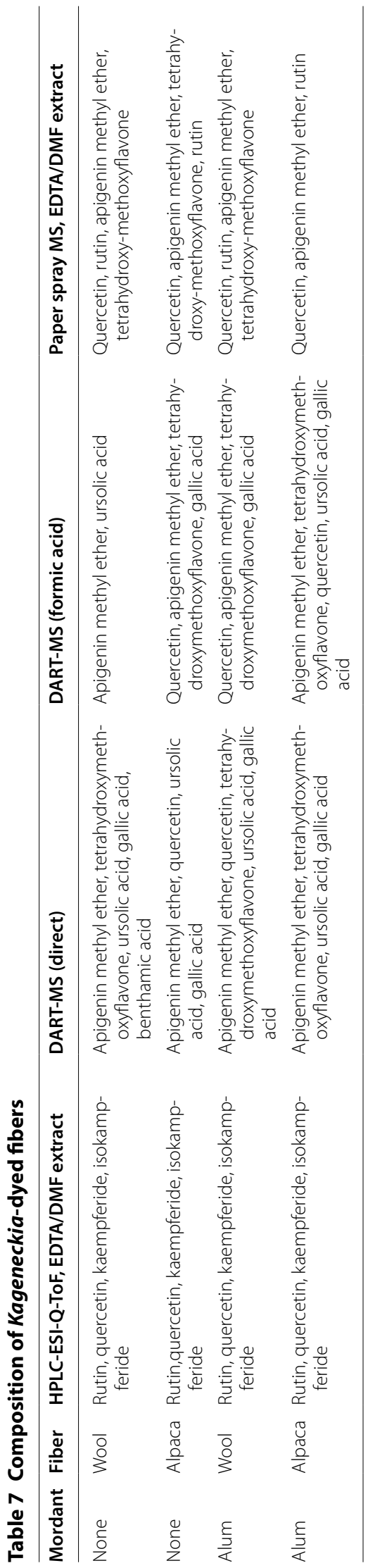




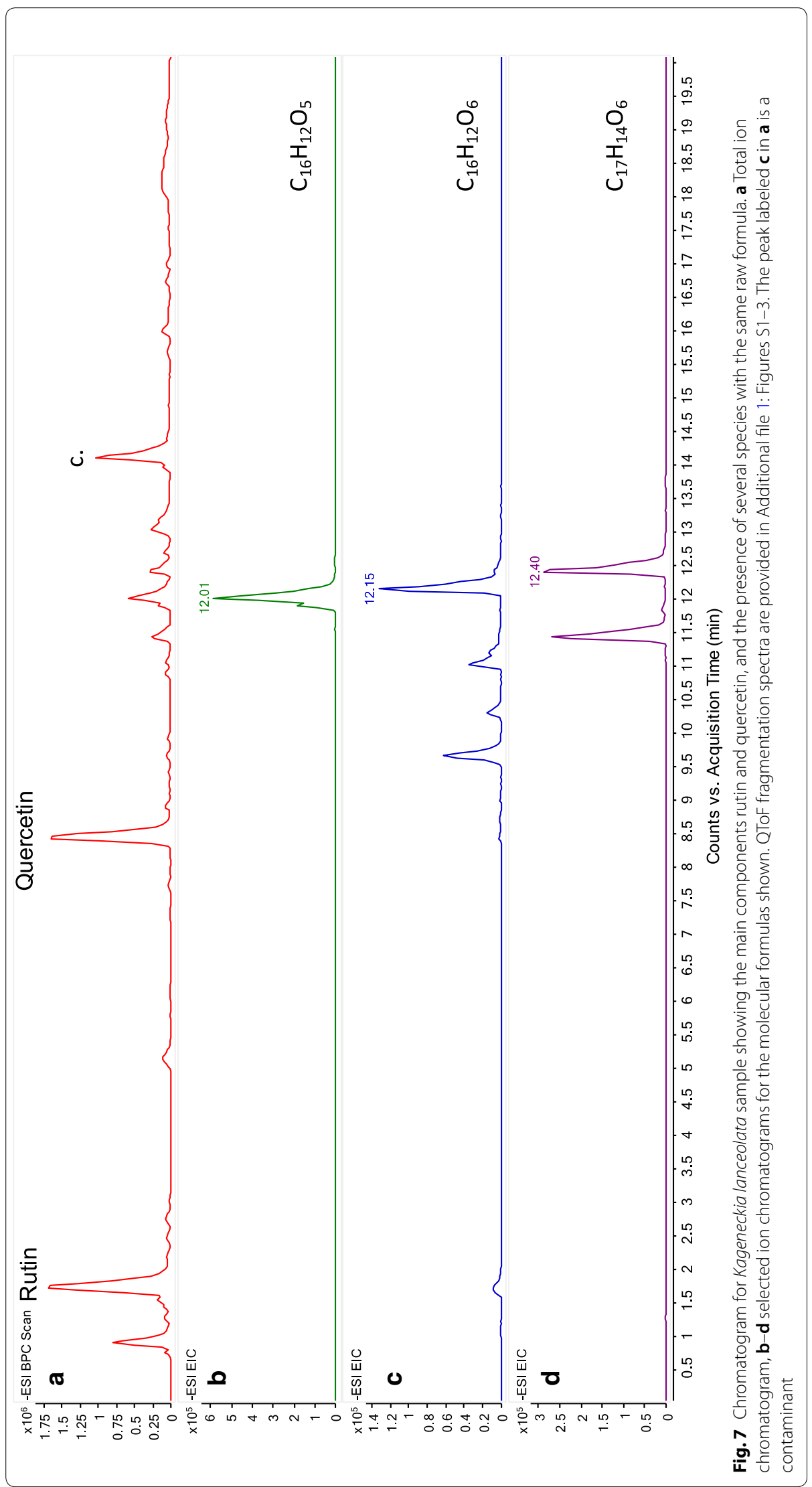


Table 8 Summary of the identified biomolecular markers in each dyed yarn from the Saltzman Collection

\begin{tabular}{|c|c|c|}
\hline Saltzman dye \# & Plant/insect genus and species & Detected molecular markers \\
\hline 16 & Relbunium hypocarpium & $\begin{array}{l}\text { Rubiadin/alizarin methyl ether; 2-methoxyanthraquinone or 1-hydroxy-2-methylanthraquinone; } \\
\text { purpurin; lucidin; munjistin; pseudopurpurin; xanthopurpurin primveroside; lucidin primvero- } \\
\text { side; galiosin }\end{array}$ \\
\hline 21 & Relbunium ciliatum & $\begin{array}{l}\text { Rubiadin/alizarin methyl ether; 2-methoxyanthraquinone or 1-hydroxy-2-methylanthraquinone; } \\
\text { purpurin; lucidin; munjistin; pseudopurpurin; xanthopurpurin primveroside; lucidin primvero- } \\
\text { side; rubiadin primveroside }\end{array}$ \\
\hline 10 & Relbunium sp. (unidentified) & $\begin{array}{l}\text { Rubiadin/alizarin methyl ether; 2-methoxyanthraquinone or 1-hydroxy-2-methylanthraquinone; } \\
\text { purpurin; lucidin; munjistin; pseudopurpurin; xanthopurpurin primveroside; lucidin primvero- } \\
\text { side; rubiadin primveroside }\end{array}$ \\
\hline 18 & Dactylopius coccus & Carminic acid; flavokermesic acid; kermesic acid; dcIl; dcIll; dcIV; dcVII \\
\hline 25 & Hypericum larcifolium & $\begin{array}{l}\text { Quercetin; rhamnetin; dihydroxyxanthone; quercetin glucorunide; methylquercetin glucorunide; } \\
\text { hypericin; pseudohypericin }\end{array}$ \\
\hline $12 \mathrm{a}$ & Kageneckia lanceolata & Quercetin; rutin; methylquercetin glucorunide; ursolic acid \\
\hline 9 & Baccharis floribunda & $\begin{array}{l}\text { Luteolin; luteolin methyl ether/trihydroxymethoxyflavone; luteolin dimethyl ether; quercetin; } \\
\text { quercetin gluconuride; tetrahydroxymethoxyflavone/(iso)rhamnetin/3-methylquercetin; } \\
\text { quercetin-3-O-rutinoside (rutin); O-caffeoyl-feruloylquinic acid; di-O-caffeoylquinic acid; api- } \\
\text { genin methyl ether; apigenin; kumatakenin; salvigenin }\end{array}$ \\
\hline
\end{tabular}

DART mass spectrum, it is easy to differentiate the Kageneckia dyes from the other yellow dyes based on the distribution of the observed compounds (Table 7).

\section{c. Paper spray MS}

The paper spray MS shows primarily the same components as the DART, with the addition of the quercetin glycoside rutin. The other major components correspond to the $[\mathrm{M}+\mathrm{H}]^{+}$or $[\mathrm{M}+\mathrm{Na}]^{+}$ions of same possible compounds proposed in the discussion of the DART mass spectra above.

\section{d. Discussion of Kageneckia results}

Because the Kageneckia dyes were previously uncharacterized, the comprehensive analysis by HPLC, particularly with the MS/MS, was critical to developing a profile of colorants. The DART-MS results showed low levels of gallic acid that were not observed by HPLC, along with the colorants identified by HPLC. Additionally, non-colorant phytochemicals characteristic of the plant source may be preserved in the yarns as well, as demonstrated with the terpenoids observed by DART-MS. Little study has been made of non-colorant phytochemicals in dyes, primarily because the sample preparation necessary for their analysis by HPLC precludes their extraction.

\section{Conclusions}

The data acquired by ambient ionisation mass spectrometry, paper spray ionisation MS and HPLC-DAD or MS for the Saltzman Collection provide the beginnings of a database of South American dye colorants that can be used in the future to study the dyes present in archaeological textiles from regions of that continent. Table 8 summarizes the results of all of the molecular markers identified in each of the analysed dyestuffs from the Saltzman Collection.

For dyes of unknown composition, the identification of the colorants is best undertaken initially through analysis by HPLC interfaced to high resolution tandem MS. This comprehensive separation and identification, provided an efficient sample extraction is used, is the only technique that permits identification of all of the compounds present in the dyes, including both aglycones and the glycosylated forms. In this work, HPLC-MS confirmed the identification of the main components of the dyes in the Saltzman Collection as suggested by the non-separative direct MS techniques. Moreover, it allowed detecting individual specific components, and revealed isomeric species. By HPLC-MS/MS, it was possible to confirm the absence of alizarin in Relbunium dyes. Differentiation between xanthopurpurin and alizarin is not possible by direct mass spectrometry approaches [9]; HPLC-DAD is generally able to differentiate these compounds due to differences in retention time as well.

DART-MS is a fast, simple method for directly identifying known colorant compounds of dyes in fibers without the need for extraction and separation when a list of possible dye colorants can either be compiled from the literature or established by a comprehensive HPLC-MS/MS analysis as described herein. The primary advantages of using DART include the rapidity with which the analysis is completed and the small amount of sample needed. For dyes where little 
is known of their composition (e.g., Kageneckia), the specific compounds present may be difficult to identify solely using DART, but the overall composition may prove useful in rapidly classifying an unknown dye. Identifying cochineal and other insect-derived red dyes in fibers solely based on DART-MS is one of the major challenges of the method at this time, though paper spray has shown that identification without chromatography is both possible and reliable. The combination of the presence of kermesic acid when formic acid is added, and the absence of the Relbunium anthraquinones in the DART mass spectra can provide sufficient evidence in mere minutes, rather than hours, for follow-up studies with HPLC on red dyes originating from South America. Future work to explore using collision induced dissociation for identifying structural isomers in mixtures will help to realize the full potential of DART-MS in dye analysis.

Paper spray ionisation supplements the DART-MS analysis by providing a way to identify the glycosides of the main colorant compounds with ambient ionisation mass spectrometry. This is particularly useful for carminic acid from cochineal insects and rutin in some of the yellow dyes reported here. In a case where an unknown red dye is present on a textile, a rapid screening with DART-MS would reveal anthraquinones characteristic of Relbunium if that plant dye were present, but may not indicate any sign of the presence of cochineal. Extraction and paper spray can rapidly confirm or exclude carminic acid by ambient ionisation MS in as little as $3 \mu \mathrm{L}$ of solution. This combined ambient mass spectrometry approach has great potential for use in identifying unknown dyes in archaeological textiles rapidly from a minimum amount of sampled material.

Finally, it has to be stressed that by direct MS techniques the analyses are fast. Because there is no chromatographic separation, the whole data collection takes only a few seconds per sample. The 64 samples (eight dyes, each on wool and alpaca, both with and without alum mordant, run directly and with formic acid added) were analysed in less than $2 \mathrm{~h}$. However, the interpretation of the spectra can be limited by the information available from comprehensive analyses that employ separation and tandem mass spectrometry. In particular, whenever the characterization of a previously unknown dyeing material is required, crosschecking of the results with those of more time consuming but more established techniques is needed. On the other hand, their ability to detect specific molecular markers can provide quick answers by enabling the fingerprinting of the mass spectrum without any sample treatment. It is also important to notice that the lack of sample pretreatment for DART analyses allowed the detection of triterpenoids in Kageneckia, which were not found by any of the other chosen methods. Other phytochemicals that are not colorants may also prove useful in differentiating dyes by DART-MS; much work remains to be done. We emphasize here the importance of validating any new approaches like these ambient ionisation mass spectrometry techniques with rigorous, established methods like HPLC that provide a comprehensive analysis.

\section{Supplementary information}

Supplementary information accompanies this paper at https://doi. org/10.1186/s40494-019-0319-1.

Additional file 1. Supplemental figures, Saltzman's notes, chemical structures and ambient mass spectra.

\section{Abbreviations}

MI: Michigan; OH: Ohio; HPLC-DAD: high performance liquid chromatographydiode array detection; HPLC-ESI-Q-ToF: high performance liquid chromatography-electrospray ionisation-quadrupole-time-of-flight; DART-MS: direct analysis in real time mass spectrometry; UCLA: University of California-Los Angeles; UV: ultraviolet; UV-vis: ultraviolet-visible; HPLC: high performance liquid chromatography; $\mathrm{HCl}$ : hydrochloric acid; EDTA: ethylenediaminetetraacetic acid; spp: species; MPC: Maria Perla Colombini; RAA: Ruth Ann Armitage; HPLC-ESI-MS: high performance liquid chromatography-electrospray-mass spectrometry; DMF: dimethylformamide; $\mathrm{Na}_{2}$ EDTA: disodium ethylenediaminetetraacetic acid; PTFE: polytetrafluoroethylene; $\mathrm{MeOH}$ : methanol; DMSO: dimethylsufoxide; DAD: diode array detection; HPLC-MS: high performance liquid chromatography-mass spectrometry; ESI: electrospray ionisation; MS: mass spectrometry; MS/MS: tandem mass spectrometry; FWHM: full width at half maximum intensity; ACN: acetonitrile; FA: formic acid; Da: daltons; V: volts; El: electron impact; GC-MS: gas chromatography-mass spectrometry; PS-MS: paper spray mass spectrometry; PEG: polyethylene glycol; mmu: millimass units; nm: nanometers; m/z: mass-to-charge ratio; dcll: Dactylopius coccus component II; dcIII: Dactylopius coccus component III; dcIV: Dactylopius coccus component IV; dcVII: Dactylopius coccus component VII; nd: not detected; TIC: total ion current chromatogram; CID: collision induced dissociation; $\mathrm{CO}_{2}$ : carbon dioxide; CO: carbon monoxide; QToF: quadrupole-time-of-flight; $\mu \mathrm{L}$ : microliters; ID: Ilaria Degano; DF: Daniel Fraser; NSF: National Science Foundation (USA); MRI-R²: Major Research Instrumentation-Recovery and Reinvestment; DCCl: Department of Chemistry and Industrial Chemistry.

\section{Acknowledgements \\ Prof. Kathryn Jakes, professor emerita at the Ohio State University gave helpful feedback on early drafts of the direct MS work, and Dr. Robert B. Cody, JEOL USA, continues to provide advice and support in all DART- and PS-MS applica- tions at EMU. Prof. Ioanna Kakoulli and Betsy Burr, both of UCLA, provided access to the Saltzman Collection and permission for sampling of the yarns. Marco Zanaboni, former student at the Pisa University, is acknowledged for sample treatment and HPLC-DAD management. All of the above have given their permission to be acknowledged in this publication.}

\section{Authors' contributions}

RAA carried out the DART-MS analyses, processed and analyzed the ambient ionistion MS data, and drafted the background and ambient ionisation MS sections of the manuscript. DF carried out the paper spray MS analyses, helped with the processing and data analysis, and contributed to the editing of the ambient ionisation sections of the manuscript. ID analyzed samples by HPLC-DAD and HPLC-MS and processed those data. MPC discussed and revised MS data. All authors read and approved the final manuscript.

\section{Funding}

The AccuTOF-DART mass spectrometer was purchased under NSF MRI-R ${ }^{2}$ award \#0959621. RAA received funding and support for supplies_-including 
the building of the paper spray ion source-and time from the Eastern Michigan University Provost's Office Faculty Research Fellowship and Research Support Awards, Eastern Michigan University Chemistry Department, and Sellers Fund. DMF received support for his time developing the paper spray methods from the Lourdes University Office of the Provost as part of his sabbatical leave at EMU. DCCI laboratory funding was provided by Pisa University.

\section{Availability of data and materials}

The datasets generated during the current study are available from the appropriate author on reasonable request: ambient ionisation (DART and paper spray) MS data from RAA, HPLC data from ID or MPC.

\section{Competing interests}

The authors declare that they have no competing interests.

\section{Author details}

${ }^{1}$ Department of Chemistry, Eastern Michigan University, Ypsilanti, MI 48197, USA. ${ }^{2}$ Department of Chemistry and Physical Sciences, Lourdes University, Sylvania, OH 43560, USA. ${ }^{3}$ Department of Chemistry and Industrial Chemistry, University of Pisa, Via Giuseppe Moruzzi, 13, Pisa 56124, Italy.

\section{Received: 12 May 2019 Accepted: 26 September 2019}

\section{Published online: 11 October 2019}

\section{References}

1. McJunkin D, McLean C, Welsh EC. The laboratory for historical colorants at UCLA. WAAC (Western Association for Art Conservation) Newsletter. 1991;13(3):21

2. Saltzman M. The identification of dyes in archaeological and ethnographic textiles. In: Carter G, editor. Archaeological Chemistry II. Advances in Chemistry, vol. 171. Washington, DC: American Chemical Society; 1978. p. 172-85.

3. Saltzman M. Analysis of dyes in museum textiles or, you can't tell a dye by its color. In: McLean CC, Connel P, editors. Textile conservation symposium in honor of Pat Reves. Los Angeles: Conservation Center, Los Angeles County Museum of Art; 1986. p. 32-9.

4. Martoglio PA, Bouffard SP, Sommer AJ, Katon JE, Jakes KA. Unlocking the secrets of the past: the analysis of archaeological textiles and dyes. Anal Chem. 1990;62(21):1123A-8A.

5. Jakes KA, Katon JE, Martoglio PA. Identification of dyes and characterization of fibers by infrared and visible microspectroscopy: Application to Paracas textiles. In: Wagner GA, Pernicka E, editors. Archaeometry'90. Basel: Birkhäuser; 1991.

6. Wallert A, Boytner R. Dyes from the Tumilaca and Chiribaya Cultures, South Coast of Peru. J Archaeol Sci. 1996;23:853-61.

7. Wouters J, Rosario-Chirinos N. Dye analysis of pre-Columbian Peruvian textiles with high-performance liquid chromatography and diode-array detection. J Am Inst Conserv. 1992;31(2):237-55.

8. Degano I, Colombini MP. Multi-analytical techniques for the study of pre-Columbian mummies and related funerary materials. J Archaeol Sci. 2009;36(8):1783-90.

9. Armitage RA, Jakes KA, Day CJ. Direct analysis in real time-mass spectroscopy for identification of red dye colorants in paracas necropolis textiles. Sci Technol Archaeol Res. 2015;1(2):60-9.

10. Saltzman M. Identifying dyes in textiles. Am Sci. 1992;80(5):474-81.

11. Burr EA. Dye analysis of archaeological Peruvian textiles using surface enhanced Raman spectroscopy (SERS). Los Angeles: UCLA; 2016.

12. Degano I, La Nasa J. Trends in high performance liquid chromatography for cultural heritage. Top Curr Chem. 2016. https://doi.org/10.1007/s4106 1-016-0020-8

13. Wouters J, Grzywacz CM, Claro A. A comparative investigation of hydrolysis methods to analyze natural organic dyes by HPLC-PDA. Stud Conserv. 2011;56:231-49.

14. Manhita A, Ferreira T, Candeias A, Dias CB. Extracting natural dyes from wool-an evaluation of extraction methods. Anal Bioanal Chem. 2011;400(5):1501-14.

15. Valianou L, Karapanagiotis I, Chryssoulakis Y. Comparison of extraction methods for the analysis of natural dyes in historical textiles by high-performance liquid chromatography. Anal Bioanal Chem. 2009;395:2175-89.
16. Sanyova J. Mild extraction of dyes by hydrofluoric acid in routine analysis of historical paint micro-samples. Microchim Acta. 2008;162:361-70.

17. Cody RB, Laramee JA, Durst HD. Versatile new ion source for the analysis of materials in open air under ambient conditions. Anal Chem. 2005;77(8):2297-302.

18. Liu JJ, Wang H, Manicke NE, Lin JM, Cooks RG, Ouyang Z. Development, characterization, and application of paper spray ionization. Anal Chem. 2010;82(6):2463-71.

19. Armitage RA, Day CJ, Jakes KA. Identification of anthraquinone dye colorants in red fibers from an ohio hopewell burial mound by direct analysis in real time mass spectrometry. Sci Technol Archaeol Res. 2015;1(2):1-10.

20. Armitage RA, Jakes KA. Sequencing analytical methods for small sample dating and dye identification of textile fibers: application to a fragment from Seip Mound Group, Ohio. Midcontinental J Archaeol. 2015;20(1):1-15.

21. Day CJ, Selvius DeRoo C, Armitage RA. Developing direct analysis in real time time-of-flight mass spectrometric methods for identification of organic dyes in historic wool textiles. In: Armitage RA, Burton JH, editors. Archaeological chemistry VIII, vol. 1147. Washington, DC: ACS; 2013. p. 69-85.

22. Geiger J, Armitage RA, Selvius DeRoo C. Identification of organic dyes by direct analysis in real time-time of flight mass spectrometry. In: Lang PL, Armitage RA, editors. Collaborative endeavors in the chemical analysis of art and cultural heritage materials. ACS Symposium Series, vol 1103. American Chemical Society; 2012. p. 123-9.

23. Williams PR, Nash JD, Henkin JM, Armitage RA. Archaeometric approaches to defining sustainable governance: wari brewing traditions and the building of political relationships in Ancient Peru. Sustainability. 2019;11(8):2333.

24. Kaktins M, Marquis M, Armitage RA, Fraser D. Mary Washington's Mended Ceramics: a study of eighteenth-century glues. In: Hunter R, editor. Ceramics in America. Milwaukee: Chipstone Foundation; 2017.

25. Fraser D, Selvius DeRoo C, Cody RB, Armitage RA. Characterization of blood in an encrustation on an African mask: spectroscopic and direct analysis in real time mass spectrometric identification of haem. Analyst. 2013;138:4470-4

26. Cody RB, Tamura J, Downard KM. Quantitation of anthocyanins in elderberry fruit extracts and nutraceutical formulations with paper spray ionization mass spectrometry. J Mass Spectrom. 2018;53(1):58-64.

27. Guo TY, Zhang ZZ, Yannell KE, Dong YY, Cooks RG. Paper spray ionization mass spectrometry for rapid quantification of illegal beverage dyes. Anal Methods. 2017;9(44):6273-9.

28. Cassels BK, Urzúa A, Cortéz M, Garbarino JA. Triterpenoid constituents of Kageneckia oblonga. Phytochemistry. 1973;12:3009.

29. Tiedemann EJ, Yang Y. Fiber-safe extraction of red mordant dyes from hair fibers. J Am Inst Conserv. 1995;34(3):195-206.

30. Degano I, Tognotti P, Kunzelman D, Modugno F. HPLC-DAD and HPLC-ESIQ-ToF characterisation of early 20th century lake and organic pigments from Lefranc archives. Herit Sci. 2017;5:7.

31. Degano I, Magrini D, Zanaboni M, Colombini MP. The Saltzman Collection: A reference database for South American dyed textiles. In: ICOM-CC 17th triennial conference preprints; 2017; Copenhagen, 4-8 September.

32. Easter $\mathrm{J}$, Steiner RR. Pharmaceutical identifier confirmation via DART-TOF. Forensic Sci Int. 2014;240:9-20.

33. Dutra Moresi CM, Wouters J. HPLC analysis of extracts, dyeings and lakes, prepared with 21 species of Relbunium. Dyes Hist Archaeol. 1997;15:85-97

34. Cardon D. Natural dyes: sources, tradition, technology and science. London: Archetype; 2007

35. Szostek B, Orska-Gawrys J, Surowiec I, Trojanowicz M. Investigation of natural dyes occurring in historical Coptic textiles by high-performance liquid chromatography with UV-Vis and mass spectrometric detection. J Chromatogr A. 2003;1012(2):179-92.

36. Mouri C, Laursen R. Identification of anthraquinone markers for distinguishing Rubia species in madder-dyed textiles by HPLC. Microchim Acta. 2012;179(1-2):105-13.

37. Stathopoulou K, Valianou L, Skaltsounis AL, Karapanagiotis I, Magiatis P. Structure elucidation and chromatographic identification of anthraquinone components of cochineal (Dactylopius coccus) detected in historical objects. Anal Chim Acta. 2013;804:264-72.

38. Antúnez de Mayolo KK. Peruvian natural dye plants. Econ Bot. 1989:43(2):181-91. 
39. Crockett S, Eberhardt M, Kunert O, Schühly W. Hypericum species in the Páramos of Central and South America: a special focus upon $\mathrm{H}$. irazuense Kuntze ex N. Robson. In: Phytochemistry reviews: proceedings of the phytochemical society of Europe. 2010;9(2):255-69.

40. Hofenk de Graaff JH. The colourful past: origins, chemistry and identification of natural dyestuffs. London: Archetype; 2004.

41. Towle MA. The ethnobotany of pre-Columbian Peru. New York: WennerGren Foundation; 1961.

42. Lopez-Perez JL, Erazo S, Delporte C, Negrete R, Munoz O, Garcia R, et al. Two new dammarane triterpenoids from Kageneckia angustifolia D. Don. Magn Reson Chem. 2005;43(11):943-7.

43. Delporte C, Munoz O, Rojas J, Ferrandiz M, Paya M, Erazo S, et al. Pharmaco-toxicological study of Kageneckia oblonga, Rosaceae. Zeitschrift Fur Naturforschung C-a J Biosci. 2002;57(1-2):100-8.
44. Wouters J, Verhecken A. The Coccid insect dyes: HPLC and computerized diode-array analysis of dyed yarns. Stud Conserv. 1989;34(4):189-200.

45. Akaike S, Sumino M, Sekine T, Seo S, Kimura N, Ikegami F. A new entclerodane diterpene from the aerial parts of Baccharis gaudichaudiana. Chem Pharm Bull. 2003;51(2):197-9.

\section{Publisher's Note}

Springer Nature remains neutral with regard to jurisdictional claims in published maps and institutional affiliations.

\section{Submit your manuscript to a SpringerOpen ${ }^{\circ}$ journal and benefit from:}

- Convenient online submission

- Rigorous peer review

- Open access: articles freely available online

- High visibility within the field

- Retaining the copyright to your article

Submit your next manuscript at $\boldsymbol{\nabla}$ springeropen.com 